\title{
A nanoformulation for the preferential accumulation in adult neurogenic niches
}

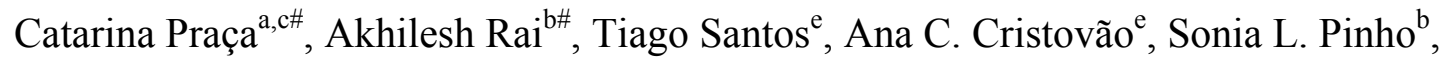 \\ Romeo Cecchelli ${ }^{\mathrm{c}}$, Marie-Pierre Dehouck ${ }^{\mathrm{c}}$, Liliana Bernardino ${ }^{\mathrm{e}}$ and Lino S. Ferreira ${ }^{\mathrm{b}, \mathrm{d}^{*}}$
}

${ }^{a}$ Doctoral Programme in Experimental Biology and Biomedicine (PDBEB), University of Coimbra, Institute for Interdisciplinary Research (IIIUC), University of Coimbra, Portugal; CNC - Center for Neuroscience and Cell Biology, University of Coimbra, Portugal

${ }^{b}$ CNC - Center for Neuroscience and Cell Biology, University of Coimbra, Portugal;

${ }^{c}$ Faculté des Sciences Jean Perrin, Université d'Artois, Lens, France

${ }^{d}$ Faculty of Medicine, University of Coimbra, Portugal

${ }^{e}$ Health Sciences Research Centre, Faculty of Health Sciences, University of Beira Interior, 6201506 Covilhã, Portugal.

"both authors contributed equally

*corresponding author:lino@uc-biotech.pt 


\section{ABSTRACT}

Stimulation of adult neurogenesis by targeting the endogenous neural stem cells (NSCs), located in hippocampus and subventricular zone (SVZ), with nanoformulations has been proposed for brain repair in cases of neurodegenerative diseases. Unfortunately, it is relatively unknown the nanoformulation properties to facilitate their accumulation in the neurogenic niches after intravenous injection. Here, we have screened different gold-based formulations having variable morphology, surface chemistry and responsiveness to light for their capacity to cross the blood brain barrier (BBB) and accumulate preferentially in the neurogenic niches. Results obtained in a human in vitro BBB model showed that gold nanoparticles (Au NPs) and gold nanorods (Au NRs) conjugated with medium density of transferrin (Tf) peptides (i.e. between 169 and 230 peptides per NP) crossed more efficiently the BBB than the remaining formulations. This is due to a relatively lower avidity of these formulations to Tf receptor (TfR) and lower accumulation in the lysosomes, as compared to the other formulations. We further show that the near infrared light (NIR) irradiation of $\mathrm{Au}$ NRs, under a certain concentration and at specific cell culture time, lead to the opening of the BBB. Finally, we demonstrate that Au NRs conjugated with $\mathrm{Tf}$ administered intravenously in mice and activated by NIR had the highest accumulation in the neurogenic niches. Our results open the possibility of targeting more effectively the neurogenic niches by controlling the properties of the nanoformulations.

Keywords: Blood-brain barrier, nanoparticles, nanorods, NIR laser, brain targeting, neurogenic niches. 


\section{INTRODUCTION}

With the increasing longevity of the population, there is an increase in brain disorders, namely neurodegenerative diseases (e.g. Alzheimer's and Parkinson's disease) and stroke [1]. Currently, there is no commercial treatment available to restore the brain function due to the limited ability of drugs to cross the blood brain barrier (BBB). Indeed, the BBB is considered as the main cause for the paucity of therapies effectiveness in most neurological disorders [2]. The transplantation of neural stem cells (NSCs) is a potential alternative to restore brain function. However, major problems related with cell survival and integration of new cells with the local circuitry have limited their application [3].

In the last few years, another therapeutic approach has been pursued based in the modulation of the endogenous NSCs [4-7]. In the adult human brain, NSCs can be found in the two germinal niches: subventricular zone (SVZ) and hippocampal subgranular zone (SGZ) [8]. Upon stimulation, these cells are able to generate neurons, astrocytes and oligodendrocytes $[9,10]$. Nanoformulations are very promising platforms to delivery molecules to the neurogenic niches, and therefore modulate the activity/differentiation of the NSC [4-7]. Most studies have administered the nanoformulations by stereotactic injection in the brain, a very invasive procedure. In this line, there is an increasing interest to achieve similar results by administrating the nanoformulations using a simpler and less invasive route, such as the intravenous administration. However, it is still relatively unknown which physico-chemical properties of nanoformulations facilitate the transport along the BBB and accumulation in the NSC niche, in order to release their cargo.

The current nanoformulation strategies for brain delivery are based on the receptor/carriermediated endocytosis and adsorptive-mediated endocytosis. The receptor/carrier-mediated endocytosis is the most common strategy for brain delivery. Several receptors have been targeted such as transferrin receptor (TfR), insulin receptor, glucose transporter, low density lipoprotein 
receptor-related protein receptor, among others [11-17]. It has been shown that modulating the affinity of antibodies [18] and the avidity of Tf-conjugated NPs against TfR [13] improve significantly NPs transport though the BBB and subsequently the efficient delivery of cargo to the brain parenchyma of mice. Another strategy for brain delivery under intense investigation is the transient opening of the BBB. Several strategies have been reported including the use of microbubbles after activation with ultrasounds $[19,20]$ and magnetic NPs after activation with magnetic actuator (hyperthermia) [21]. All these platforms are promising, and it is possible that they have potential to target the neurogenic niches; however, that potential was not demonstrated so far.

In the current work, we have screened different nanoformulations having variable morphology (spherical or rod shape), surface chemistry (Au NPs- $\mathrm{Tf}_{50 / 230 / 375}$ and $\mathrm{Au}$ NRs- $\mathrm{Tf}_{17 / 169 / 317}$ ) and responsiveness of $\mathrm{Au} \mathrm{NRs}$ to light for their capacity to cross the BBB and accumulate preferentially in the neurogenic niches (Fig. 1). Although several inorganic and organic nanoformulations [11-17, 22-24] have been explored to cross the BBB; no study has shown its preferential accumulation in the neurogenic niches. We have used Au NPs/Au NRs because these formulations make easy the bioconjugation and characterization using several techniques compared to organic ones. It is expected that the principles identified in this work can inspire new formulations in which the Au core can be replaced by a NIR-sensitive organic core conjugated with biomolecules. Initially, we have screened the ability of the formulations to cross in vitro human BBB model using a transwell system [25]. During this screening, we have monitored the BBB stability after incubation with the formulations and BBB apparent permeability. In vitro data shows that $\mathrm{BBB}$ integrity and permeability depend on the surface chemistry and concentration of the formulations along with NIR laser exposure. NIR laser exposure of the Au NR formulations leads to the opening of the $\mathrm{BBB}$ due to a local heating effect. In agreement with the in vitro results, animal studies show that $\mathrm{Au}$ NPs- $\mathrm{Tf}_{230}$ and $\mathrm{Au}$ NRs- $\mathrm{Tf}_{169}$ were the most effective formulations to 
cross the $\mathrm{BBB}$ and accumulate in mice brain. We further show that $\mathrm{Au}$ NRs- $\mathrm{Tf}_{169}$ administered intravenously in mice and activated by a NIR laser had the highest accumulation in the neurogenic niches. Overall, our results demonstrate the targeting of a nanoformulation to the neurogenic niche in small rodents. It is expected that the use of photo-illumination techniques currently used in the setting of photodynamic therapy in humans (e.g. fiber-optic catheters, laser fiber /LED balloon adapter)[26] may offer further opportunities for the clinical translation of this approach.

\section{Material and methods}

2.1. Synthesis of Au NPs and Au NRs. Citrate-reduced Au NPs were synthesized using the Turkevich method [27]. In general, a $\mathrm{HAuCl}_{4}$ solution $(90 \mathrm{~mL}, 1 \mathrm{mM})$ was boiled at $100^{\circ} \mathrm{C}$ followed by addition of sodium citrate (120 mg dissolved in $10 \mathrm{~mL}$ of Milli-Q water). The solution was boiled until the solution color turned from light yellow to ruby-red. Au NRs were synthesized as published before.[28] $\mathrm{Au}$ seed solution was prepared by adding $\mathrm{HAuCl}_{4}(12.5 \mu \mathrm{L}, 0.1 \mathrm{M})$ in cetyltrimethylammonium bromide (CTAB) $(5 \mathrm{~mL}, 0.1 \mathrm{M})$ solution. This solution was vigorously stirred using a magnetic stirrer. After 5 min of stirring, an ice-cold sodium borohydride solution $(0.6 \mathrm{~mL}, 10 \mathrm{mM})$ was added in the solution and kept stirring for another $2 \mathrm{~min}$. Then the solution was left at $25^{\circ} \mathrm{C}$ for $8 \mathrm{~min}$. In the next step, $\mathrm{AgNO}_{3}$ solution $(3.2 \mathrm{~mL}, 50 \mathrm{mM})$ was added in CTAB solution $(200 \mathrm{~mL}, 0.1 \mathrm{M})$ and mixed gently. $\mathrm{HAuCl}_{4}(1 \mathrm{~mL}, 0.1 \mathrm{M})$ was added to the previous solution, changing the color of solution from transparent to yellow-orange. Then, ascorbic acid solution $(1.5 \mathrm{~mL}, 100 \mathrm{mM})$ was added into the Au-CTAB solution and mixed gently, followed by addition of $1.5 \mathrm{~mL}$ of seed solution. The resulting solution was left at $28^{\circ} \mathrm{C}$ for $2 \mathrm{~h}$. Au NRs were purified from spherical Au NPs using centrifugation at $9000 \mathrm{~g}$ for $30 \mathrm{~min}$.

2.2 Conjugation of Tf peptide to Au NPs and Au NRs. Tf peptide with a terminal cysteine aminoacid (THRPPMWSPVWPC) was purchased from Caslo Laboratory, Denmark. The peptide was synthesized by conventional solid-phase synthesis, purified by high performance liquid 
chromatography, and characterized by matrix assisted laser desorption ionization time-of-flight (MALDI-TOF) mass spectroscopy (MS). The purity of the peptide was $96 \%$.

The conjugation of $\mathrm{Tf}$ peptide to the formulations was initiated by the reaction of $\mathrm{Tf}$ with amine-PEG-maleimide. The ratio of amine-PEG-maleimide to Tf was 0.02: $0.04 \mu$ mol (for Au NPs$\mathrm{Tf}_{50}$ ), 0.3: $0.6 \mu \mathrm{mol}$ (for Au NPs-Tf $f_{230}$ ) and 1: $1.5 \mu \mathrm{mol}$ (for Au NPs- $\mathrm{Tf}_{375}$ ) and these ratios were reacted in PBS $(1 \mathrm{~mL}, \mathrm{pH} 7.0,100 \mathrm{mM})$ for $1 \mathrm{~h}$ followed by purification of conjugate using an Amicon centrifugal unit (cut-off $3 \mathrm{kDa}$ ) at $9000 \mathrm{~g}$ for $5 \mathrm{~min}$. The purification was done twice to remove free Tf peptides. The collected conjugates for both ratios was reacted with Au NPs (12 mg) for $12 \mathrm{~h}$ followed by addition of thiol-PEG $(0.5 \mathrm{mmol}, 2 \mathrm{kDa})$ for $30 \mathrm{~min}$. Tf conjugated Au NPs were pelleted by centrifugation at $14.000 \mathrm{rpm}$ for $20 \mathrm{~min}$, and unbound conjugates and thiol-PEG were removed with supernatant. The Au NP pellets were resuspended in sterile $10 \mathrm{mM}$ PBS (pH 7.2). To prepare $\mathrm{Tf}$ conjugated $\mathrm{Au}$ NRs, the ratio of amine-PEG-maleimide to $\mathrm{Tf}$ was $0.02: 0.04$ $\mu \mathrm{mol}$ (for Au NRs- $\mathrm{Tf}_{17}$ ), 0.2: $0.4 \mu \mathrm{mol}$ (for $\mathrm{Au}$ NRs- $\mathrm{Tf}_{169}$ ) and 1: $1.5 \mu \mathrm{mol}$ (for $\mathrm{Au} \mathrm{NRs}-\mathrm{Tf}_{317}$ ) was used and these ratios were reacted in PBS $(1 \mathrm{~mL}, \mathrm{pH} 7.0,100 \mathrm{mM})$ for $1 \mathrm{~h}$ followed by purification as described above. Prior to functionalization of PEG-Tf conjugate, $1 \mathrm{mg} / \mathrm{mL}$ of Au NRs were reacted with $0.1 \mathrm{mg}$ of thiol-PEG $(2 \mathrm{kDa})$ at room temperature for 2 days to remove CTAB from the surface of Au NRs. PEG modified Au NRs were centrifuged at $9000 \mathrm{~g}$ for $30 \mathrm{~min}$ to remove the unreacted PEG. PEG-modified Au NRs were used to further functionalized with different PEG-Tf conjugate as described above. To backfill the Tf functionalized Au NPs or NRs, $0.5 \mathrm{mg}$ of thiolmPEG (2kDa) was incubated with $1 \mathrm{mg} / \mathrm{mL}$ of Au NPs-Tf $\mathrm{T}_{50 / 230 / 375}$ and Au NRs- $\mathrm{Tf}_{17 / 169 / 317}$ under dark condition for $1 \mathrm{~h}$ followed by centrifugation to remove unbound PEG.

2.3. Quantification of the number of Tf peptide per Au NP/Au NR. The amount of immobilized peptide was determined indirectly by estimating the peptide that remained in solution after the conjugation. The peptides in the stock solution (PEG-Tf conjugate) and supernatants of Au NPs-Tf and Au NRs-Tf were quantified by spectrophotometry at $280 \mathrm{~nm}$ using the Beer-Lambert law and 
an extinction coefficient of $5600 \mathrm{M}^{-1} \mathrm{~cm}^{-1}$. The amount of immobilized peptide was estimated by subtracting the amount of peptide in supernatants from the initial added amount. The number of peptide per NP/NR was obtained by dividing the number of peptide per $\mathrm{mL}$ of solution by the number of NPs/NRs per mL of solution.

2.4. Characterization of the formulations: TEM and FTIR analyses. The morphology and size of $\mathrm{Au}$ NPs and Au NRs were analysed by TEM. The sample was prepared by drop-casting the Au NPs/NRs on Formvar carbon-coated grids and allowed to dry before performing TEM measurement. TEM analyses were carried out on a Jeol JEM-1011 microscope operated at an accelerating voltage of $100 \mathrm{kV}$. A minimum of 100 NPs was measured using Image $\mathrm{J}$ software for the particle size analysis. For FTIR analysis, Au NPs-PEG, Au NPs-Tf ${ }_{230}, \mathrm{Au}$ NRs-PEG and Au NRs- $\mathrm{Tf}_{169}$ were lyophilized. FTIR analyses were performed in transmission (KBr) mode using Thermo Scientific spectrophotometer at $4 \mathrm{~cm}^{-1}$ resolution with 64 scans between 4000 and $400 \mathrm{~cm}^{-1}$. $2 \mathrm{mg}$ of dried samples were mixed with $198 \mathrm{mg}$ of $\mathrm{KBr}$ powders and pelletized at 10 tons of pressure to make discs. FTIR measurement was performed immediately after preparing the $\mathrm{KBr}$ disc to avoid the absorption of moisture.

2.5. Characterization of the formulations: NP size analyses. The size of more than $100 \mathrm{Au}$ NPs was estimated from TEM images using Image $\mathbf{J}$ software. In case of Au NRs, length and width of more than $100 \mathrm{NRs}$ were measured and then the aspect ratio (length/width) of each NR was calculated. Frequency distribution of sizes of NPs and aspect ratios of NRs was plotted.

2.6 Characterization of the formulations: zeta potential analyses. Zeta $(\zeta)$ potential of the Au NPs, Au NRs, Au NPs-Tf and Au NRs-Tf (suspended in $1 \mathrm{mM} \mathrm{KCl)} \mathrm{was} \mathrm{measured} \mathrm{by} \mathrm{light}$ scattering via a Zeta PALS Zeta Potential Analyzer (Brookhaven Instruments Corporation). All data were recorded with at least 6 runs with a relative residual value (measure of data fit quality) of 0.03 .

2.7. Characterization of the formulations: stability in cell culture media. $\mathrm{Au}$ NPs, Au NPs$\mathrm{Tf}_{230}, \mathrm{Au} \mathrm{NRs}$ and $\mathrm{Au}$ NRs-Tf ${ }_{169}$ were incubated with EGM-2 media containing serum (2\%). At 
different time intervals, absorbance of Au NPs and Au NRs were measured at 520 and $780 \mathrm{~nm}$, respectively.

2.8. Preparation of the in vitro human BBB model. The in vitro BBB model was generated according to our previous work [25]. Briefly, CD34+ were isolated from human umbilical cord blood and differentiated into ECs by cultivation in endothelial cell medium (EGM-2; Lonza) supplemented with FBS (20\%, Life technologies) and VEGF $_{165}(50 \mathrm{ng} / \mathrm{mL}$, PeproTech Inc) in $1 \%$ $(w / v)$ gelatin-coated $24-w e l l$ plates $\left(2 \times 10^{5}\right.$ cells/well $)$. ECs were observed in culture dishes after 15-20 days. Cells were expanded in 1\% (w/v) gelatin-coated $100 \mathrm{~mm}$ Petri dishes (BD Falcon) in EGM-2 medium.

The BBB model was established by coculturing the $\mathrm{CD} 34^{+}$-derived ECs with bovine pericytes for 6 days. The bovine pericytes were seeded at a cell density of $45 \times 10^{3}$ in the bottom of a 12 well plate (Costar) coated with $1 \%$ gelatin and one day after $\mathrm{CD} 34^{+}$-derived ECs were seeded at a density of $80 \times 10^{3}$ in Matrigel-coated (BD Biosciences) $0.4 \mu \mathrm{m}$ Transwell inserts (Costar). Coculture model was kept in EGM-2 medium supplemented with FBS (2\%, v/v), gentamycin (50 $\mu \mathrm{g} / \mathrm{mL}$, Biochrom AG) and bFGF (1 ng/mL) for 6 days before tests.

2.9. In vitro human BBB model: Lucifer yellow permeability measurements. We have placed the Transwell insert having CD34+-derived ECs in a new 12 well plate containing EBM-2 media. Filter inserts were filled with EBM-2 media containing the fluorescent integrity marker Lucifer yellow (LY, $20 \mu \mathrm{M}$, Life Technologies). The plates were placed on an orbital shaker for $1 \mathrm{~h}$ followed by the withdraw of media from the receiver compartment. For each experiment, at least three inserts with cells and without cells were tested. The fluorescence of the samples (inserts with cells and without cells) was quantified using the wavelengths 430/530 (excitation/emission). The Pe values were generated through the blue-norna brain exposure simulator (http://www.bluenorna.com). The monolayer integrity was accepted for values between $0.6-1.2 \times 10^{-3} \mathrm{~cm} / \mathrm{min}$. The permeability data were normalized against the control (without treatment). 


\subsection{In vitro human BBB model: transendothelial electrical resistance (TEER)}

measurements. TEER $\left(\mathrm{Ohmxcm}{ }^{2}\right)$ of $\mathrm{CD}^{4} 4^{+}$-derived ECs on Transwell filters was measured using the Millicell-ERS 2 (Electrical Resistance System, Millipore). The resistance of Matrigel-coated inserts was subtracted from the resistance obtained in the presence of the endothelial cultures according to the followed equation: TEER $=[($ TEER, cells $)-(T E E R$, insert $) \times A]$, where $A$ is the area of the filter $\left(\mathrm{cm}^{2}\right)$. For each experiment, at least three inserts with cells and without cells were tested. The TEER representing the monolayer integrity was accepted for values higher than 50 $\Omega \times \mathrm{cm}^{2}$.

2.11. In vitro human BBB model: immunocytochemistry analyses. Cells were fixed in cold paraformaldehyde (4\%, v/v, Alfa Aesar) for $10 \mathrm{~min}$ at room temperature and permeabilized with Triton X-100 (0.1\%, Fluka) for $10 \mathrm{~min}$. The cells were then blocked with BSA (1\%, w/v, Sigma) solution for at least 30 min followed by incubation with primary antibody (ZO-1: 1:200 dilution, Invitrogen; VE-Cadherin: 1:100 dilution, Santa Cruz; LAMP2: 1:40, R\&D Systems) during $1 \mathrm{~h}$ at room temperature. After washing, the cells were stained with secondary antibody (Alexa 488 antirabbit: 1:200 dilution; Alexa 555 anti-mouse: 1:200 dilution) for $30 \mathrm{~min}$ in dark at room temperature. The nuclei of the cells were counterstained with DAPI and cells mounted with cellmounting medium from DAKO. All images were taken using confocal microscopy (Zeiss) with a $40 \times$ oil objective. For colocalization analysis the JaCoP pluggin for ImageJ [29] was used. The \% of colocalization was determined by the Mander's coefficient, which measures the pixel overlap, independent of pixel intensities. The value of the coefficient varies from 0 to 1 , with 0 meaning that both channels are mutually exclusive and 1 meaning that all pixels with fluorescence from one channel (e.g. red) overlap with pixel in the other channel (e.g. green). The data express the fraction of NRs that overlap with Lamp2.

2.12. In vitro human BBB model: cell viability. Cell viability was assessed by a cell permeable resazurin-based solution, PrestoBlue ${ }^{\mathrm{TM}}$ (Life Technologies). PrestoBlue ${ }^{\mathrm{TM}}$ Reagent was added 
directly to $\mathrm{CD} 34^{+}$-ECs in culture medium (1:10), incubated for $90 \mathrm{~min}$, and the fluorescence was quantified in the plate reader (BioTek) using the wavelengths 560/590 (excitation/emission). The fluorescence of the treated cells was then normalized by the control (no treatment).

2.13. In vitro human BBB model: flow cytometry analyses. The expression of TfRs was evaluated by flow cytometry. Six days after the coculture of CD34+-ECs with pericytes, Au NRs$\mathrm{Tf}_{169}$ and $\mathrm{Au}$ NRs- $\mathrm{Tf}_{317}$ were added to the donor compartment in EGM-2 media for $2 \mathrm{~h}$ in shaking conditions at $37^{\circ} \mathrm{C}$ and $5 \% \mathrm{CO}_{2}$. After $2 \mathrm{~h}$, the filters containing the $\mathrm{CD} 34^{+}$-ECs were transferred to a new 12 well plate and cells were washed and harvested from the filters by Tryple Express (Life Technologies) for 5-8 min. Cells were then ressuspended in PBS supplemented with FBS (5\%, $\mathrm{v} / \mathrm{v})$. The cell suspensions were then incubated with a PE-conjugated antibody against the TfR (R\&D Systems). Accuri C6 was used for the acquisition and FlowJo software for data analysis.

2.14. In vitro human BBB model: nanoformulation internalization studies. To evaluate the internalization, the cells were incubated for $2 \mathrm{~h}$ with different density of Tf-conjugated or bare $\mathrm{Au}$ NPs or Au NRs in EGM-2 media (with all supplements except FBS and gentamycin/amphotericin) supplemented with FBS (2\%, v/v), gentamycin $(50 \mu \mathrm{g} / \mathrm{mL})$ and bFGF $(1 \mathrm{ng} / \mathrm{mL})$, in shaking conditions. The cells were then washed and harvested from the filters by Tryple Express for 5-8 min. The cell suspension was then washed $3 \mathrm{x}$ with PBS, resuspend and lyophilized. The Au content was assessed by ICP-MS. For the determination of $\mathrm{Kd}$, the cells were incubated with increasing concentrations of $\mathrm{Au}$ NRs-Tf $\mathrm{Tf}_{17 / 169 / 317}$ for $2 \mathrm{~h}$. NRs internalized cells were isolated and ICP-MS analyses were performed (see below). The obtained data were fitted using Langmuir isotherm model. The $\mathrm{Kd}$ of different data was estimated using the linear curve-fitting model of Langmuir isotherm equation.

2.15. In vitro human BBB model: inductively coupled plasma-mass spectrometer (ICP-MS) analyses. An Agilent 7700x ICP-MS was used to determine Au concentration. Samples were introduced via a concentric glass nebulizer with a free aspiration rate of $0.3 \mathrm{rps}$, a Peltier-cooled 
double pass glass spray chamber, and a quartz torch. A peristaltic pump carried samples from an Integrated Autosampler I-AS (Agilent) to the nebulizer. Au standards were prepared by serial dilution of a solution containing $1000 \mathrm{mg} / \mathrm{L} \mathrm{Au}$ in 5\% $\mathrm{HCl}$ (Panreac). A five-point calibration curve was made over a concentration range of $2-100 \mu \mathrm{g} / \mathrm{L} \mathrm{Au} .{ }^{193} \mathrm{Ir}$ was used as the internal standard. Data acquisition was done using peak hopping with an integration time of $0,7 \mathrm{~s}$ per mass, a total adquisition time of $10.47 \mathrm{~s}$ and three replicates per sample.

2.16. In vitro human BBB model: temperature profile of $\mathrm{Au} \mathrm{NR}-\mathbf{T f}_{169}$. The in vitro $\mathrm{BBB}$ model was incubated with different concentrations of $\mathrm{Au} \mathrm{NR}-\mathrm{Tf}_{169}$ for $10 \mathrm{~min}$ and then exposed to a NIR laser for $2 \mathrm{~min}$. The cell culture media containing Au NR-Tf ${ }_{169}$ was immediately removed and the temperature of the ECs in the BBB model as well as the cell culture medium was quantified by a FLIR SC5650 infrared camera. In a separate experiment, Au NR-Tf ${ }_{169}(50 \mu \mathrm{g} / \mathrm{mL})$ was incubated with the in vitro $\mathrm{BBB}$ for $2 \mathrm{~h}$ followed by removal of media, exposure to a NIR laser and measurement of the temperature by an infrared camera.

\subsection{In vitro human BBB model: apparent permeability analyses of Au NPs-Tf and Au NRs-}

Tf. To evaluate the permeability of $\mathrm{Au}$ NPs- $\mathrm{Tf}_{50 / 230 / 375}, \mathrm{Au}$ NRs- $\mathrm{Tf}_{17 / 169 / 317}$, bare $\mathrm{Au} \mathrm{NP}$ and bare $\mathrm{Au}$ NRs across the BBB, the experiments were done as follow. The acceptor compartments of the 12 wells of BBB models were filled with $1.5 \mathrm{~mL}$ EGM-2 media (with all supplements except FBS and gentamycin/amphotericin) supplemented with FBS (2\%, v/v), gentamycin (50 $\mu \mathrm{g} / \mathrm{mL})$ and bFGF (1 ng/mL). Different concentrations $(0-100 \mu \mathrm{g} / \mathrm{mL})$ of Au NPs-Tf, Au NRs-Tf, Au NPs and Au NRs were added to the donor compartment having EGM-2 media for $2 \mathrm{~h}$ in shaking conditions at $37^{\circ} \mathrm{C}$ and $5 \% \mathrm{CO}_{2}$. After $2 \mathrm{~h}$, the media from the different compartments were withdrawn and stored at $4^{\circ} \mathrm{C}$; cells were washed and fresh media was added in the compartments and kept in incubator for $24 \mathrm{~h}$. Simultaneously, media and pericytes from the bottom well were collected for ICP-MS analyses to quantify the transport of Au NPs and Au NRs. In case of light exposure experiments, the 
cells incubated with Au NRs for $2 \mathrm{~h}$ were washed with media to remove the non-internalized Au NRs followed by irradiation with the NIR laser of wavelength $780 \mathrm{~nm}$ for $2 \mathrm{~min}$ at $2 \mathrm{~W} / \mathrm{cm}^{2}$.

In a different set of experiments, cells were incubated with $\mathrm{Au}$ NRs- $\mathrm{Tf}_{169}$ for $10 \mathrm{~min}$ and irradiated (in the presence of the NRs). Afterwards, cells were either maintained in the presence of the $\mathrm{Au}$ NRs-Tf $\mathrm{T}_{169}$ for additional $110 \mathrm{~min}$ or immediately washed with fresh media to remove the non-internalized $\mathrm{Au}$ NRs-Tf ${ }_{169}$ and incubated for additional $110 \mathrm{~min}$. At the end, cells were again washed and characterized or cultured for additional $24 \mathrm{~h}$. In both cases, bottom cell culture media was collected to assess the gold content. In all of the experiments, assessments of monolayer integrity and permeability measurement were done as described above for LY.

Apparent permeability (Papp) for each sample was determined by equation 1:

$$
\text { Papp }=\left(\frac{d Q}{d t}\right) *\left(\frac{1}{A}\right) *\left(\frac{1}{C_{0}}\right)(\mathrm{cm} / \mathrm{s})
$$

$\mathrm{dQ} / \mathrm{dt}$ refers to the amount of gold present in the acceptor compartment at the function of time $(\mu \mathrm{g} / \mathrm{s})$, A to the area of the insert $\left(\mathrm{cm}^{2}\right)$ and $\mathrm{C}_{0}$ to the initial concentration of the NPs/NRs added to the donor compartment $(\mu \mathrm{g} / \mathrm{mL})$.

The percentage of transport was calculated using the following equation 2 :

$$
T \%=\left(\frac{C_{A}(t)}{C_{D}\left(t_{0}\right)}\right) * 100
$$

$\mathrm{C}_{\mathrm{A}}(\mathrm{t})$ is the amount of NPs/NRs present in the acceptor donor after 2 or $24 \mathrm{~h}$ and $\mathrm{C}_{\mathrm{D}}\left(\mathrm{t}_{0}\right)$ is the initial amount added into the donor compartment at time $0 \mathrm{~h}$. For ICP-MS measurement, samples were digested with $1 \% \mathrm{HCl}$ before performing the measurements.

2.18. In vitro human BBB model: inhibition of transport of Au NPs-Tf and Au NRs-Tf. The acceptor compartments of the 12-wells BBB models were filled with fresh 1.5 mL EGM-2 media (with all supplements except FBS and gentamycin/amphotericin) supplemented with FBS (2\%, $\mathrm{v} / \mathrm{v})$, gentamycin $(50 \mu \mathrm{g} / \mathrm{mL})$ and $\mathrm{bFGF}(1 \mathrm{ng} / \mathrm{mL})$. The acceptor compartment was incubated with dansylcadaverine (DCad; $100 \mu \mathrm{M}$ in EGM-2) for $30 \min [30]$. Au NPs-Tf N $_{230}(100 \mu \mathrm{g} / \mathrm{mL})$ or $\mathrm{Au}$ 
NRs- $\mathrm{Tf}_{169}(50 \mu \mathrm{g} / \mathrm{mL})$ were then added to the donor compartment in EGM-2 media for $2 \mathrm{~h}$ in shaking conditions at $37^{\circ} \mathrm{C}$ and $5 \% \mathrm{CO}_{2}$, maintaining the inhibitor present. After $2 \mathrm{~h}$, the media from the different compartments were withdrawn, cells were washed and fresh media was added in the compartments and kept in incubator for $24 \mathrm{~h}$. Media and pericytes from bottom well of the transwell was collected for ICP-MS analyses to quantify the concentration of Au. In case of laser activation experiments, the cells incubated with $\mathrm{Au}$ NRs for $2 \mathrm{~h}$ were washed with media to remove the noninternalized $\mathrm{Au}$ NRs followed by irradiation with the NIR laser of wavelength $780 \mathrm{~nm}\left(2 \mathrm{~W} / \mathrm{cm}^{2}\right)$ for 2 min. As control, we used cells incubated with Au NPs- $\mathrm{Tf}_{230}$ and Au NRs- $\mathrm{Tf}_{169}$ in the absence of the inhibitor.

2.19. Animal testing: nanoformulation accumulation in the brain. All animal experimental procedures were performed in accordance with institutional animal house, national and European Community guidelines (86/609/EEC; 2010/63/EU; DGAV protocol 0421/000/000/2016). C57BL/6 (8 weeks) inbred strain was used for the in vivo experiments. The animals were housed in cages placed in a ventilated, temperature-controlled room. The animals were kept at $22^{\circ} \mathrm{C}$ room temperature, 45-65\% humidity, and under a $12 \mathrm{~h}$ light/dark cycle. A commercial diet (pellets) and filtered water were available ad libitum.

Mice were anesthetized with $4 \%$ isoflurane and then kept with $1.5 \%$ isoflurane by mask and separated randomly in several groups: Au NPs-Tf ${ }_{230 / 375}$, Au NPs, Au NRs-Tf ${ }_{169}$ or Au NRs (200 $\mu \mathrm{L}$, $5 \mathrm{mg} / \mathrm{mL}$ ) were injected in the tails of the anesthetized mice. In case of laser activation experiments, the animals were anesthetized, the hair above the skull shaved and the skin cleaned before exposing to a $780 \mathrm{~nm}$ diode laser at $2 \mathrm{~W} / \mathrm{cm}^{2}$ with a circular output beam diameter of $1 \mathrm{~cm}$ for the duration of $2 \mathrm{~min}$. The activation was performed $1 \mathrm{~h}$ after the administration of Au NRs-Tf ${ }_{169}$. Two hours after the administration of NPs/NRs, the animals were anesthetized with sodium pentobarbital and perfused with a solution of $\mathrm{NaCl}$. For ICP-MS analyses, different organs and brain regions (SVZ, hippocampus and whole brain) were then excised and washed with PBS. Different brain regions 
were lyophilized and analyzed by ICP-MS. For ICP-MS data, the amount of Au NPs/NRs present in different regions of the brain was estimated based on the theoretical amount of $\mathrm{Au}(0)$ present in $\mathrm{Au}$ NPs/NRs. The amount of Au NPs-Tf/Au NRs-Tf present in different regions of the brain was normalized against bare Au NPs/NRs. \% of injected dose was calculated by dividing the amount of NPs/NRs present in different regions of the brain by the initial amount injected in the animal.

2.19. Animal testing: nanoformulation toxicity in the brain. Mice were randomly separated into 3 groups (Saline control; $\mathrm{Au}$ NRs-Tf $169 ; \mathrm{Au} \mathrm{NRs}-\mathrm{Tf}_{169}+\mathrm{NIR}$ ) and individually anesthetized with isoflurane. The animals were then intravenously injected into the lateral tail vein with saline (200 $\mu \mathrm{L})$ or saline containing $\mathrm{Au}$ NR-Tf ${ }_{169}(5 \mathrm{mg} / \mathrm{mL})$. Isoflurane was discontinued and animals were allowed to recover. In case of laser activation experiments, mice skulls were irradiated with a 780 $\mathrm{nm}$ diode laser at $2 \mathrm{~W} / \mathrm{cm}^{2}$ post $1 \mathrm{~h}$ administration of Au NRs-Tf $\mathrm{T}_{169}$. To assess the neurotoxicity, animals were maintained for 3 days before euthanasia with an overdose of ketamine/xylazine mixture. Upon euthanasia, mice were transcardially perfused with $0.9 \% \mathrm{NaCl}$ to rinse out blood followed by $4 \%$ paraformaldehyde in PBS. Fluoro-Jade C (FJC) staining was performed to assess neurotoxicity and was carried out as previously described [31] with some modifications. Briefly, coronal sections $(30 \mu \mathrm{m})$ encompassing the SVZ region were first processed for immunohistochemistry to detect Nestin-, Sox2- and NeuN-positive cells and for nuclear staining with Hoechst, by incubating in PBS containing $10 \%$ FBS and $0.1 \%$ Triton $\mathrm{X}-100$ for at least $1 \mathrm{~h}$, at room temperature. Sections were then incubated with primary antibody mouse anti-NeuN (1:1000, Merck Millipore) or mouse anti-Nestin (1:500), goat anti-Sox-2 (1:500, Santa Cruz) in PBS containing 5\% FBS, overnight at $4^{\circ} \mathrm{C}$. After several rinses with PBS, sections were incubated with secondary antibody anti-mouse $546(1: 1000)$ or anti-goat $546(1: 1000)$ and anti-mouse $647(1: 1000)$ in PBS, for $1 \mathrm{~h}$ at room temperature. Prior to FJC staining, sections were mounted onto poly-Llysine coated glass slides and then air-dried for $48 \mathrm{~h}$. Slides were transferred to $0.06 \%$ potassium permanganate solution for $2 \mathrm{~min}$ and rinsed for $2 \mathrm{~min}$ in distilled water. Slides were incubated for 
$10 \mathrm{~min}$ in a $0.0005 \%$ solution of FJC (Millipore, Temecula, CA) and DAPI (1:500) dissolved in $0.1 \%$ acetic acid vehicle. The slides were rinsed three times $(1 \mathrm{~min}$ each $)$ with distilled water. Excess water was drained with a paper towel, and the slides were air-dried and cleared in xylene for at least $1 \mathrm{~min}$ and cover-slipped with DPX (Sigma) nonfluorescent mounting media. Digital images were acquired using the Zeiss Axiovert 200 inverted confocal microscope under a 40× magnification.

2.20. Animal testing: BBB integrity analyses. Mice were randomly separated into 6 groups (Saline control; Saline+ NIR control; Au NRs-Tf ${ }_{169} 2$ h; Au NRs-Tf ${ }_{169} 24 \mathrm{~h} ;$ Au NRs-Tf ${ }_{169}+$ NIR 2 h; $\mathrm{Au} \mathrm{NRs-Tf}{ }_{169}+\mathrm{NIR} 24 \mathrm{~h}$ ) and individually anesthetized. Then the animals were intravenously injected into the lateral tail vein with saline $(200 \mu \mathrm{L})$ or saline containing $\mathrm{Au} \mathrm{NR}-\mathrm{Tf}_{169}(5 \mathrm{mg} / \mathrm{mL})$. Isoflurane was discontinued and animals were allowed to recover. In case of light exposure experiments, the heads of mice were irradiated with the NIR laser of wavelength $780 \mathrm{~nm}$ for $2 \mathrm{~min}$ at $2 \mathrm{~W} / \mathrm{cm}^{2}$ post $1 \mathrm{~h}$ administration of $\mathrm{Au}$ NRs- $\mathrm{Tf}_{169}$. All groups were intravenously injected with Evans blue dye (Sigma, $25 \mathrm{mg} / \mathrm{Kg}$ ) $90 \mathrm{~min}$ before euthanasia. Animals were euthanized with an overdose of ketamine/xylazine mixture $2 \mathrm{~h}$ or $24 \mathrm{~h}$ after saline or Au NR injection. Upon euthanasia, mice were transcardially perfused with $0.9 \% \mathrm{NaCl}$ to rinse out blood followed by $4 \%$ paraformaldehyde in PBS. Brains were collected and post-fixed for $24 \mathrm{~h}$ in $4 \%$ paraformaldehyde at $4^{\circ} \mathrm{C}$. Fixed brains were then washed thoroughly in PBS and sectioned coronally into $1 \mathrm{~mm}$-thick slices using a brain slicer matrix. Both whole brains and respective sections were imaged using a ChemiDoc $^{\text {TM }}$ MP (Bio-Rad). Evans Blue fluorescence readings were acquired with a filter set between $665-715 \mathrm{~nm}$ with the same exposure time throughout all experimental groups. Mean gray values were quantified using ImageJ software $(\mathrm{NIH})$ on 8-bit grayscale images. Colorimetric images were also acquired to provide an outline of the samples imaged.

2.21. Statistical Analyses. For analysis involving three or more groups, ANOVA was used, followed by a Newman-Keuls post-test. For analysis of two groups, a unpaired $t$-test was used. 
Statistical analysis was performed using GraphPad Prism software (San Diego, CA, USA). Results were considered significant when $P \leq 0.05$.

\section{RESULTS}

\subsection{Preparation of the nanoformulations}

For the initial screening, we have selected 12 formulations with different morphology, number of Tf peptide per formulation and light responsiveness (Fig. 1A). Au NPs were chosen due to their biocompatibility, easy bioconjugation, morphological variety and easy to follow in vivo by imaging and analytical tools. We have selected $\mathrm{Tf}$ to target the brain and facilitate the transport of formulations through the BBB. TfR receptor is highly expressed in BBB endothelial cells (ECs) and recent studies have shown that this receptor is a good target for brain delivery $[11,32,33]$. We have prepared formulations with variable number of Tf peptide (Fig. 1A) as this parameter has an important effect in their transport across the BBB [32, 33]. Au NPs having an average diameter of $12 \mathrm{~nm}$ and $\mathrm{Au}$ NRs with an average size of $46.7 \times 13.7 \mathrm{~nm}$ were selected for the screening (Fig. 1A). We have selected Au NPs with an average diameter of $12 \mathrm{~nm}$ because small NPs can cross the BBB easily $[11,14,34]$. Au NRs were selected due to their morphology and absorption properties in the NIR region $[35,36]$. Our hypothesis is that $\mathrm{Au}$ NRs could be activated in the brain under exposure of NIR laser, leading to a local photothermal effect and consequently the permeabilization of the BBB. 

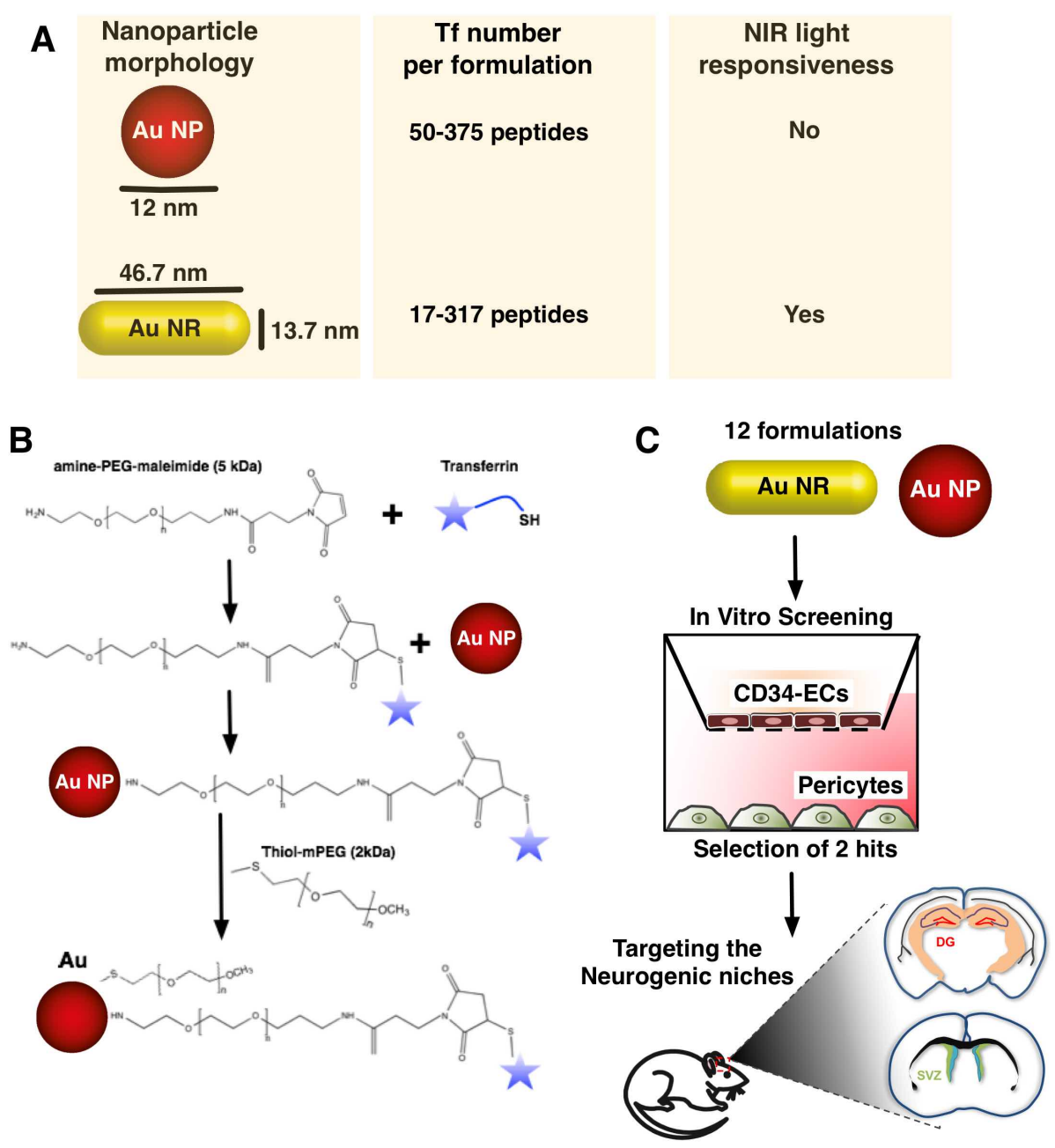

Fig 1. Schematic representation of the formulations properties, conjugation methodologies and protocol followed to demonstrate the targeting of the formulations to the neurogenic niches. (A) Scheme showing the properties of the NP formulations selected in this work. Spherical and rodshape Au formulations were conjugated with different numbers of Tf peptides. In case of Au NPs: 50 (Au NPs-Tf 50 ; low density of Tf), 230 (Au NPs-Tf ${ }_{230}$; medium density of Tf) and 375 (Au NPs$\mathrm{Tf}_{375}$; high density of $\mathrm{Tf}$ ). In case of $\mathrm{Au}$ NRs: 17 (Au NRs-Tf ${ }_{17}$; low density of $\mathrm{Tf}$ ), 169 (Au NRs$\mathrm{Tf}_{169}$; medium density of $\mathrm{Tf}$ ) and 317 (Au NRs-Tf ${ }_{317}$; high density of $\mathrm{Tf}$ ). In some experiments, NIR light was used to activate the Au NRs. (B) Schematic representation of the preparation of Tf-PEG conjugate and immobilization of Tf-PEG conjugate on the surface of Au NPs and Au NRs. The thiol group of Tf peptides reacts with a maleimide group of maleimide-PEG-amine $(5 \mathrm{kDa})$; the conjugate purified by dialysis and then reacted with Au NPs and Au NRs. The Tf-PEG conjugated NPs/NRs were backfilled with methoxy-terminated polyethylene glycol molecules (mPEG, $2 \mathrm{kDa}$ ) to prevent the unspecific adsorption of proteins on the surface of NPs/NRs. (C) Schematic representation of the methodology used to select NP formulations to target the neurogenic niches.

To prepare the nanoformulations with variable numbers of Tf peptides, the Tf peptide (1.5 $\mathrm{KDa})$ was reacted initially with $\mathrm{NH}_{2}$-PEG-maleimide $(5 \mathrm{kDa})$. The maleimide group reacts with the thiol group of $\mathrm{Tf}$ to form a stable thioether bond. The Tf derivative was then incubated with Au NPs 
or Au NRs to allow the reaction of the free amine group of PEG with formulations (Fig. 1B). 50 (Au NPs-Tf 5 ; low density of Tf), 230 (Au NPs-Tf ${ }_{230}$; medium density of $\mathrm{Tf}$ ) and 375 (Au NPs$\mathrm{Tf}_{375}$; high density of Tf) Tf peptides per Au NP and 17 (Au NRs-Tf ${ }_{17}$; low density of Tf), 169 (Au NRs- $\mathrm{Tf}_{169}$; medium density of $\left.\mathrm{Tf}\right)$ and $317\left(\mathrm{Au} \mathrm{NRs}_{-} \mathrm{Tf}_{317}\right.$; high density of $\left.\mathrm{Tf}\right) \mathrm{Tf}$ peptides per $\mathrm{Au}$ NRs were prepared (Fig. 1A). The peptide density achieved was in the range of other values reported in the literature $[11,37]$. It is important to note that the peptide surface densities of AuNP$\mathrm{Tf}_{50}\left(0.11\right.$ peptide $\left./ \mathrm{nm}^{2}\right)$, AuNP-Tf $230\left(0.51\right.$ peptide $\left./ \mathrm{nm}^{2}\right)$ and $A u N P-\mathrm{Tf}_{370}(0.82$ peptide/nm²) are higher than the ones observed for AuNR-Tf 19 (0.0094 peptide/nm²), AuNR-Tf 169 (0.084 peptide $\left./ \mathrm{nm}^{2}\right)$ and AuNR-Tf $317\left(0.16\right.$ peptide $\left./ \mathrm{nm}^{2}\right)$. Because the distribution of Tf peptides is likely heterogeneous in $\mathrm{Au}$ NRs based in previous studies [38-41] (these studies show that thiolcontaining molecules mostly prefer to bind to end faces compared to side faces of Au NRs), the number of Tf peptide in each formulation rather than the density of Tf peptide per $\mathrm{nm}^{2}$ of NP or NR was used. The formulations were then coated with $2 \mathrm{kDa}$ thio-mPEG molecules $(0.25 \mu \mathrm{mol}$; this represents 7 and 5 PEG molecules per $\mathrm{nm}^{2}$ of $\mathrm{Au}$ NP and $\mathrm{Au}$ NR, respectively) to increase its stability in cell culture media and to improve its specific binding to a targeted cell population by overcoming the inhibitory effect of the protein corona $[42,43]$.

To characterize the formulations, we have performed size, zeta potential and FTIR analyses as well as stability measurements on cell culture media. Au NPs-Tf had an average diameter of 12 nm, similarly to bare Au NPs (Supplementary Fig. 1A1, A2,); however UV-vis spectra showed a red shift in the surface plasmon resonance (SPR) band of Au NPs from 520 to $525 \mathrm{~nm}$ after conjugation with Tf-PEG- $\mathrm{NH}_{2}$ likely due to a change in local dielectric environment of $\mathrm{Au}$ NPs (Supplementary Fig. 1B) [44]. Zeta potential measurements showed that Au NPs-Tf were positively charged (between +1 and $+3 \mathrm{mV}$ ) while bare Au NPs were negatively charged $(-19 \pm 2 \mathrm{mV}$, due to the presence of sodium citrate on the surface of NPs; see Materials and Methods) (Supplementary Fig. 1C). Moreover, both Au NPs and Au NPs-Tf were stable in EGM-2 cell culture media for at 
least 24 h (Supplementary Fig. 3A). Regarding Au NRs, transmission electron microscopy (TEM) results showed an average size of $46.7 \times 13.7 \mathrm{~nm}$ (Supplementary Fig. 2A1. A2). UV-vis spectra showed a red shift of $5 \mathrm{~nm}$ in NIR region compared to Au NRs, indicating the conjugation of Tf peptide on the surface of NRs (Supplementary Fig. 2B). Zeta potential characterization showed that $\mathrm{Au}$ NRs were positively charged due to the presence of surfactant cetyltrimethylammonium bromide (CTAB) on the surface of NRs (Supplementary Fig. 2C; see Materials and Methods). Moreover, Au NRs-Tf ${ }_{169}$ were stable in EGM-2 media for at least 24 h (Supplementary Fig. 3B). FTIR analyses were performed to confirm the conjugation of the Tf peptide in the surface of $\mathrm{Au}$ NPs and Au NRs. The peaks at $1656 \mathrm{~cm}^{-1}$ (amide I) and $1540 \mathrm{~cm}^{-1}$ (amide II) in both formulations indicate the presence of Tf peptide (Supplementary Fig. 1D, 2D). The same signature was not observed when Au NPs/Au NRs were only modified by PEG (Supplementary Fig. 1D, 2D).

\subsection{Effect of the nanoformulations in the integrity of the in vitro human BBB model}

Next, we evaluated the integrity and transport properties of the in vitro BBB model after exposure to the formulations for $2 \mathrm{~h}$ (Fig. 2A). We have selected a $2 \mathrm{~h}$ exposure of formulations to $\mathrm{BBB}$ model based on previous studies performed in vitro and in vivo $[11,14,45]$. The upper chamber cell culture media was then removed, the cells washed, and feeded with new cell culture media. We measured the TEER and permeability to Lucifer yellow, before and after exposure to the formulations at time $24 \mathrm{~h}$ (Fig. 2A). 

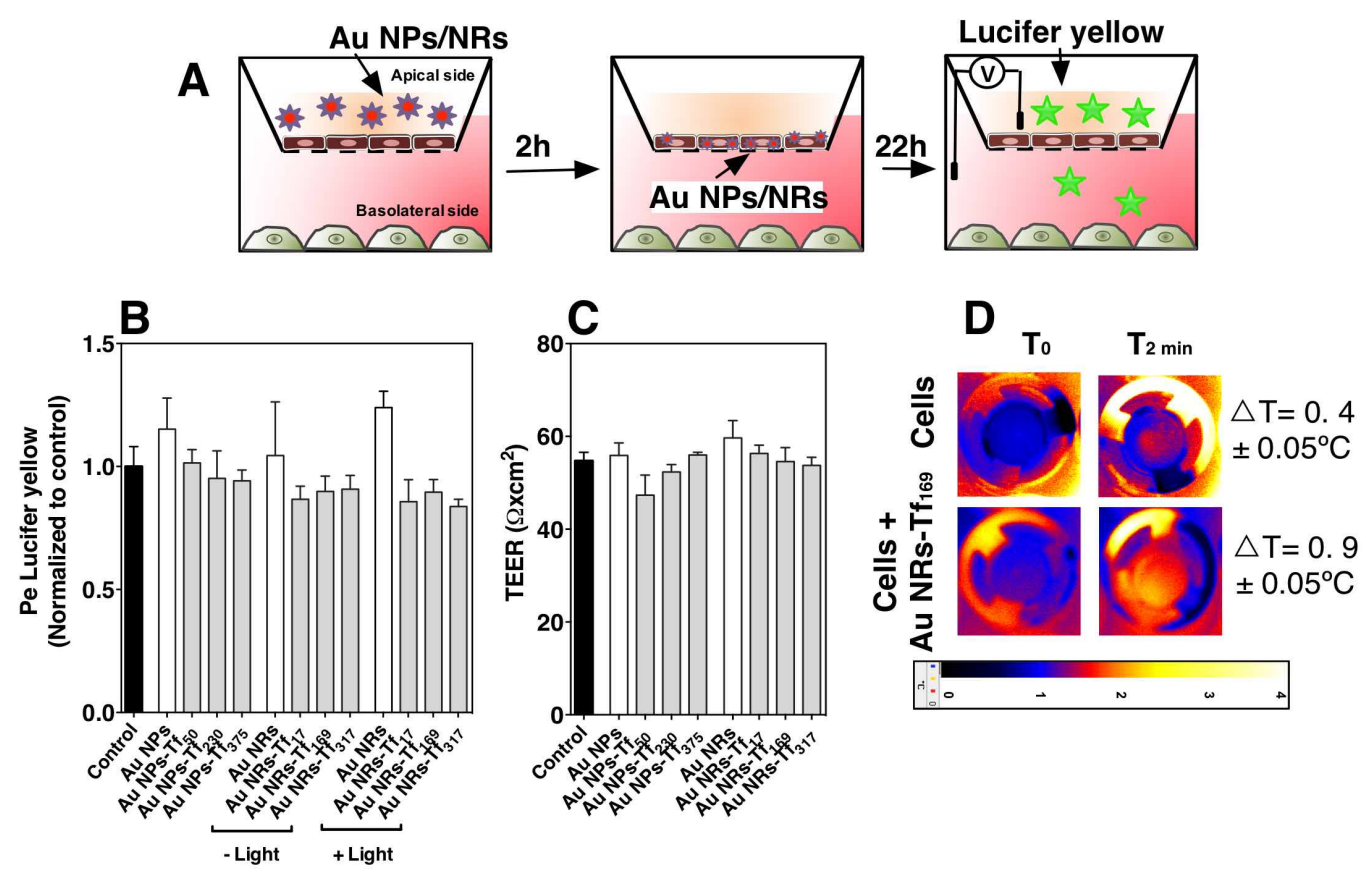

Fig 2. Impact of the formulations in the integrity of an in vitro human BBB model. (A) Schematic representation of the protocol used for permeability and TEER measurement. The BBB model was incubated with the formulations for $2 \mathrm{~h}(50-100 \mu \mathrm{g} / \mathrm{mL})$, after which the cell medium containing the non-internalized NPs was removed, cells were washed and incubated with fresh medium. The BBB model was either exposed or not to a NIR laser $\left(2 \mathrm{Wcm}^{-2}, 2 \mathrm{~min}, 780 \mathrm{~nm}\right)$, and then incubated for additional $22 \mathrm{~h}$. At the end, the monolayer integrity of the BBB model was evaluated. (B) Paracellular permeability to Lucifer yellow (LY) and (C) TEER $24 \mathrm{~h}$ post exposure of BBB model to the formulations. Permeability was normalized against the control condition (without NPs/NRs). In the control, the paracellular permeability to LY was in average $0.8 \pm 0.05 \times 10^{-3} \mathrm{~cm} / \mathrm{min}$, while the TEER value for T0 (before exposure to the NP formulations) was $55.7 \pm 2.2 \Omega \times \mathrm{cm}^{2}$. Results are Mean \pm SEM ( $n=3$ independent experiments, 3 technical replicates per independent experiment). (D) Thermal profile measurements were measured in ECs with and without internalised Au NRs$\mathrm{Tf}_{169}$. In both cases, the cells were exposed to a NIR laser for $2 \mathrm{~min}, 2 \mathrm{Wcm}^{-2}$. The measurements were performed immediately after the NIR laser irradiation. Results are Mean \pm SEM (3 technical replicates).

Our results show that $\mathrm{Au} \mathrm{NPs} / \mathrm{Au}$ NPs-Tf $\mathrm{T0/230/375}_{1}$ and $\mathrm{Au} \mathrm{NRs} / \mathrm{Au} \mathrm{NR}-\mathrm{Tf}_{17 / 169 / 317}$ up to concentrations of $100 \mu \mathrm{g} / \mathrm{mL}$ do not increase significantly the permeability to Lucifer yellow and decrease TEER, indicating that the formulations have no measurable damage effect in the barrier properties (Fig. 2B, C). Because the permeability results of the in vitro BBB model were slightly affected by Au NRs (however without statistical difference) we performed cytotoxicity analyses, using the same experimental conditions used for the permeability and TEER analyses. Our results 
confirm that both $\mathrm{Au}$ NRs or Au NRs-Tf ${ }_{169}$ (with or without light activation) did not induce toxicity on ECs (Supplementary Fig. 4). Finally, immunofluorescence analyses of VE-Cadherin and tight junction protein ZO-1 confirm that the intercellular contacts between ECs of BBB model are not affected after incubation with all the formulations tested (Supplementary Fig. 5). To exclude the possibility that our in vitro $\mathrm{BBB}$ model was not responsive to the damage effect of the formulations, we have exposed the BBB model to mannitol a well-known BBB disruptive agent. As expected, there was a significant increase ( $\sim 2$ fold increase as compared to non-treated BBB model) in the permeability to Lucifer yellow (Supplementary Fig. 6A).

Local heat generated by Au NRs internalized by brain ECs and irradiated by a NIR laser might open the BBB. Therefore, we have examined the integrity of the in vitro $\mathrm{BBB}$ model incubated with Au NRs for $2 \mathrm{~h}$, removed the cell medium containing the non-internalized Au NRs, added new cell culture medium and finally we irradiated the BBB model with a NIR laser (wavelength $780 \mathrm{~nm}, 2 \mathrm{Wcm}^{-2}, 2 \mathrm{~min}$ pulse). As control, we have evaluated the permeability of the barrier in the same radiation conditions but without incubation with Au NRs. The NIR laser alone had no effect in the permeability and TEER of the in vitro BBB model (Supplementary Fig. 7). Similarly, the integrity of the BBB is not significantly affected after Au NRs or Au NRs-Tf ${ }_{17 / 169 / 317}$ $(50 \mu \mathrm{g} / \mathrm{mL})$ incubation and NIR laser exposure after $0 \mathrm{~h}$ (data not shown) and $22 \mathrm{~h}$ (Fig. 2B, C). Under these conditions, no significant increase in the temperature was observed in the ECs of the BBB model, as measured by a thermal camera (Fig. 2D), and thus explaining the absence of BBB opening. Is it possible that the amount of internalized $\mathrm{Au}$ NRs- $\mathrm{Tf}_{169}$ (approximately $10 \%$ of the initial concentration, therefore $2.5 \mu \mathrm{g}$ per $8 \times 10^{4}$ cells) is not sufficient to induce a heating effect in order to transiently open the BBB.

We then asked whether the Au NRs could open the BBB before their cellular internalization. In this case, we incubated the in vitro human BBB model for 10 min with different concentrations of Au NRs-Tf ${ }_{169}$ (Fig. 3A). In one set of experiments (set A), the Au NRs (without washing after the 
10 min incubation) were activated by a NIR laser and let them in the presence of the cells for 110 min. In another set of experiments (set B), the Au NRs were activated by a NIR laser, the noninternalized Au NRs were removed from the Transwell, and cells incubated for 110 min with fresh medium. 

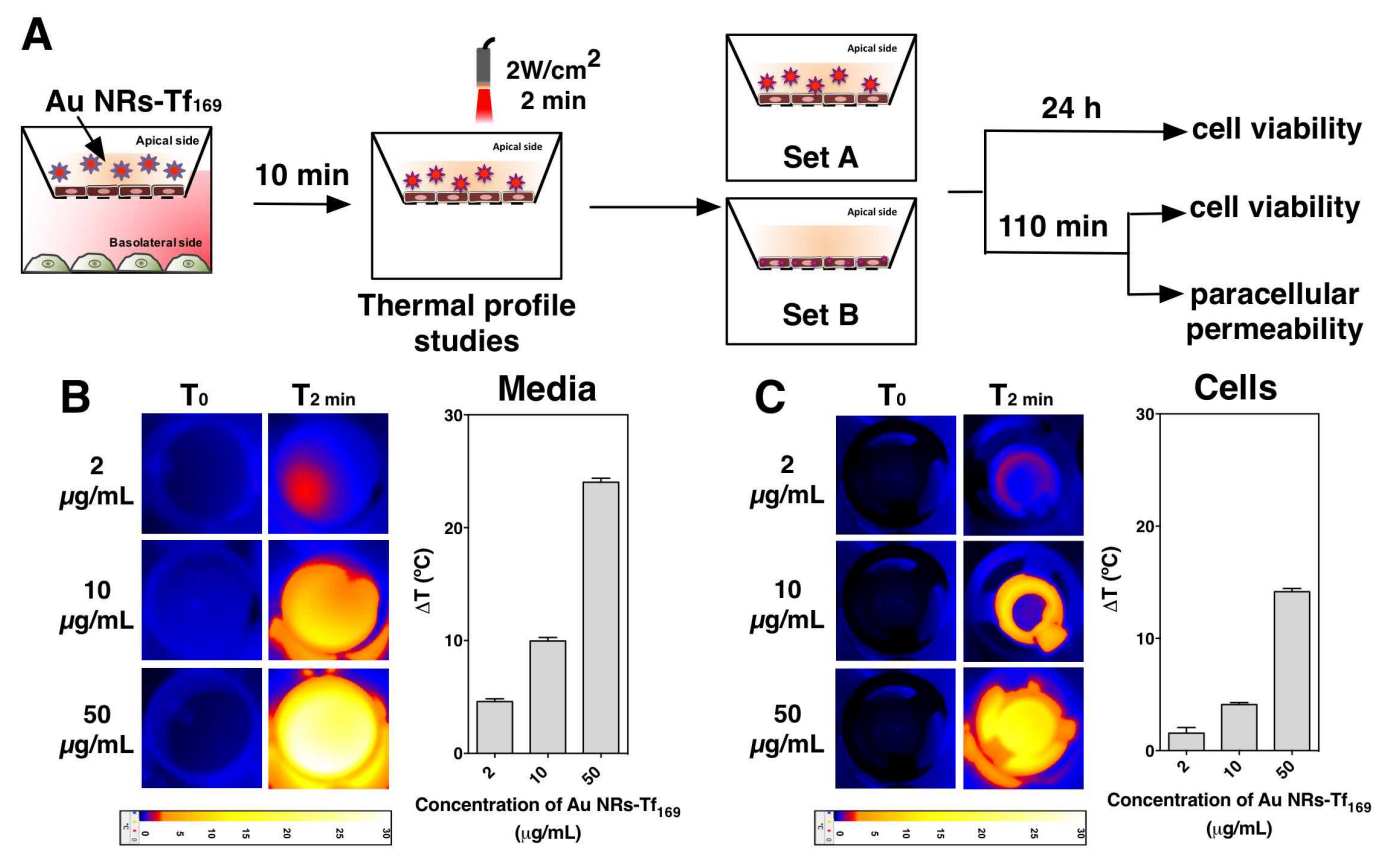

E.1

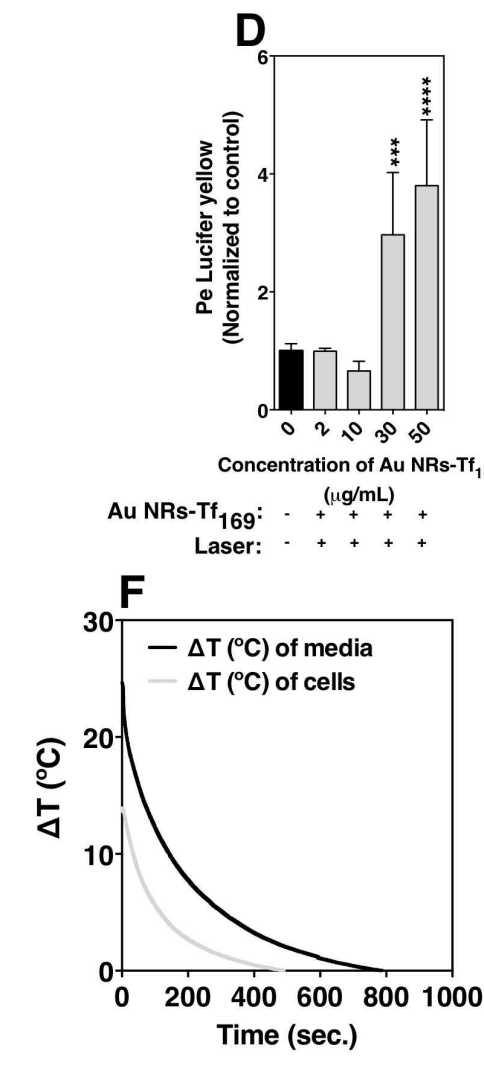

E.2
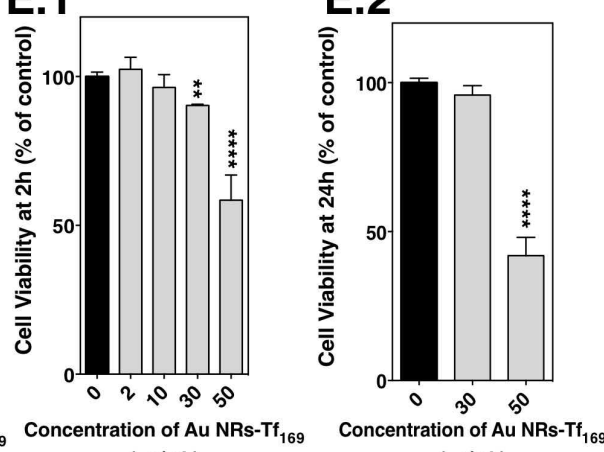

$(\mu \mathrm{g} / \mathrm{mL})+$

$(\mu \mathrm{g} / \mathrm{mL})$

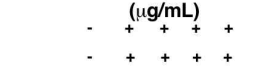

G.2

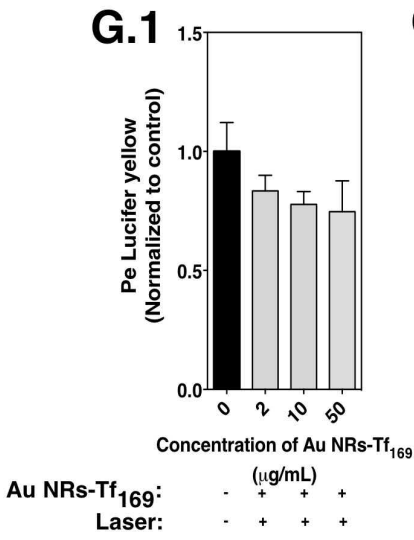

G.2

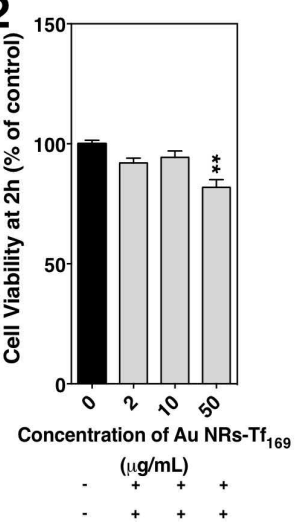

Fig 3. BBB opening by Au NRs. (A) Schematic representation of the protocol used. The in vitro human BBB model was incubated with different concentrations of $\mathrm{Au} \mathrm{NRs}-\mathrm{Tf}_{169}$ for $10 \mathrm{~min}$, and then irradiated with a $780 \mathrm{~nm}$ laser $\left(2 \mathrm{Wcm}^{-2}\right)$ for $2 \mathrm{~min}$. Thermal profile analyses were then performed in the cell culture media and ECs. Cell viability and paracellular permeability was used to assess the impact in the ECs monolayer. (B) Variance of temperature in media after NIR laser exposure. (C) Variance of temperature in cells after NIR laser exposure. Results are Mean \pm SEM (3 technical replicates per condition). (D) Paracellular permeability of the BBB to LY at $2 \mathrm{~h}$ post- 
incubation with Au NRs. Viability of the EC monolayer was evaluated by a Presto Blue assay at $2 \mathrm{~h}$ (E.1) and $24 \mathrm{~h}$ (E.2). In D and E, results are Mean \pm SEM ( $\mathrm{n}=2$ independent experiments, 3 technical replicates per independent experiment). (F) Decay of temperature in cells and cell culture media after the irradiation of Au NRs- $\mathrm{Tf}_{169}(50 \mu \mathrm{g} / \mathrm{mL})$ for $10 \mathrm{~min}$. Results are Mean \pm SEM (3 technical replicates per condition). In another set, Au NRs were immediately removed from the cells after NIR laser exposure and (G.1) paracellular permeability to LY and (G.2) cell viability by a Presto Blue assay were assessed. Results are Mean \pm SEM ( $n=2$ independent experiments, 3 technical replicates per independent experiment). In D, E and G, statistical analyses were performed by One-way ANOVA followed by a Dunnett post-test (comparison with the control, i.e., in vitro BBB model not exposed to nanoformulations). ${ }^{*} * P<0.01$, $* * * P<0.001$ and $* * * * P<0.0001$.

In set A experiments, after NIR irradiation occurs a significant increase in the temperature of the cell culture media and ECs (Fig. 3B, C), and the increase is dependent in the concentration of $\mathrm{Au}$ NRs. Interestingly, our results indicate that $\mathrm{Au}$ NRs can open the BBB after their irradiation with a NIR laser, as evaluated by an increase in the paracellular permeability to Lucifer yellow (Fig. 3D), the disruption of the intercellular contacts between ECs (Supplementary Fig. 8A) and an increase in the permeability to the Au NRs (Supplementary Fig. 8B). However, the opening only occurs for certain concentrations of Au NRs-Tf ${ }_{169}(30$ and $50 \mu \mathrm{g} / \mathrm{mL})$ and when $\mathrm{Au}$ NRs continued in contact with brain ECs after NIR activation (i.e. $110 \mathrm{~min}$ ) (Fig. 3D, E.1, E.2). In these conditions, the decrease in the temperature to basal levels takes between 8 and 10 min (Fig. 3F). Importantly, the opening of the BBB by medium concentration of $\mathrm{Au} \mathrm{NRs-Tf}{ }_{169}(30 \mu \mathrm{g} / \mathrm{mL})$ lead to a slight decrease in EC viability immediately after the NIR irradiation (Fig. 3E.1); however, the cell viability was similar to control at time $24 \mathrm{~h}$ (Fig. 3E.2). In contrast, the opening of the BBB by high concentrations of $\mathrm{Au}$ NRs $(50 \mu \mathrm{g} / \mathrm{mL})$ lead to a significant decrease in EC viability immediately after the NIR irradiation as well as time $24 \mathrm{~h}$. In set B experiments, the Au NRs could not open the BBB after irradiation with a NIR laser, as the paracellular permeability to Lucifer yellow was not significantly affected (Fig. 3G). These results showed that the presence of the media containing the Au NRs after irradiation had impact in the opening of the BBB. 
Overall, our results indicate NR formulations internalized by brain ECs, with or without NIR laser irradiation, had no significant effect in the integrity of the in vitro BBB model, at least under the concentrations tested. Our results suggest that the low intracellular concentration of NRs $(2.5 \mu \mathrm{g}$ per $8 \times 10^{4}$ cells) is unable to increase significantly the intracellular temperature (less than $1^{\circ} \mathrm{C}$, Fig. 2D). However, the irradiation of NR formulations that are internalized (i.e. intracellular) and noninternalized (i.e. extracellular) by brain ECs, which remain in contact with cells for a certain time, are able to transiently open the BBB (for certain concentrations) without a major impact in terms of cell viability. According to our results, it seems that the extracellular content of $\mathrm{Au} \mathrm{NRs}$ (concentrations above $10 \mu \mathrm{g} / \mathrm{mL}$ and below or equal to $30 \mu \mathrm{g} / \mathrm{mL}$ ) (Fig. 3D and E) dictates the thermal effect and consequently the BBB opening. The underlie cellular mechanism is still unclear and should be explored in future studies. In the sections below we will study in more detail the transport of the nanoformulations in the absence of BBB opening, and thus controlled by receptormediated endocytosis.

\subsection{Cellular internalization of the nanoformulations}

To demonstrate that our in vitro human BBB model is a suitable model to evaluate the permeability of the nanoformulations, we evaluated the expression of TfR in ECs (Fig. 4A, B). Our results show that $76.6 \pm 10 \%$ of the cells (Fig. 4B.1) express TfR which is similar to the values reported for other brain ECs [46]. We then asked whether the conjugated Tf density of the Au NPs or $\mathrm{Au}$ NRs could affect their internalization by the in vitro human BBB model. For that purpose, the internalized nanoformulations were quantified by inductively coupled plasma mass spectrometry (ICP-MS) (Fig. 4A, C, D). All the formulations were internalized by the ECs at different extents. Interestingly, the formulations with medium density of $\mathrm{Tf}\left(\mathrm{Au}\right.$ NPs- $\mathrm{Tf}_{230}$ or Au NRs-Tf $\mathrm{N}_{169}$ ) exhibited the highest internalization compared to the remaining ones (Fig. 4C, D). Thus, the density of the Tf 
peptide on the surface of the NPs/NRs seems to play an important role in the internalization process.

\section{$\begin{array}{lll}\text { B.1 } & \text { B.2 } & \text { B.3 }\end{array}$}

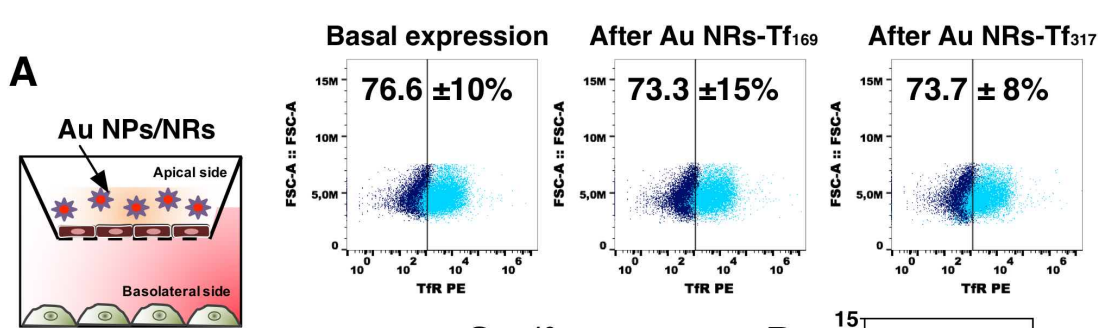

$\downarrow 2 h$
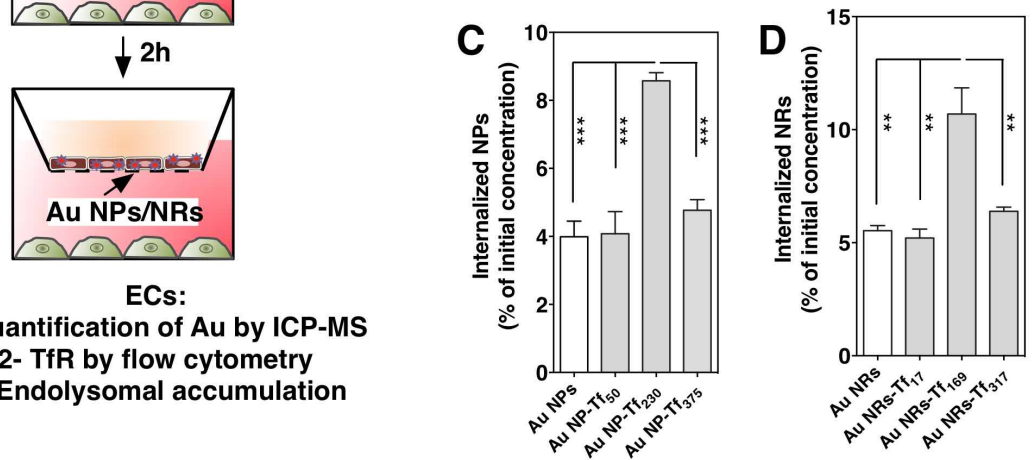

ECs:

1-Quantification of Au by ICP-MS

2- TfR by flow cytometry

3- Endolysomal accumulation

E.1 $1_{\text {Au NRs-Tf169 }}$

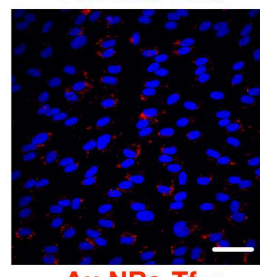

Au NRs-Tf $f_{317}$

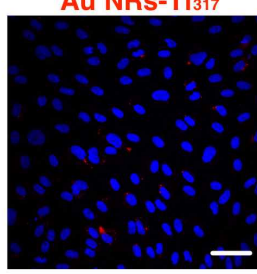

Lamp2

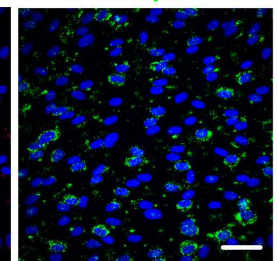

Lamp2

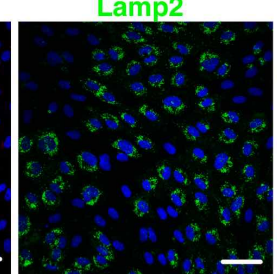

Merge

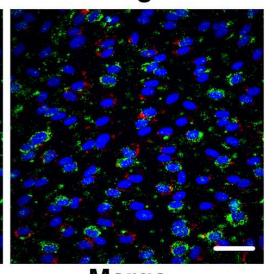

Merge

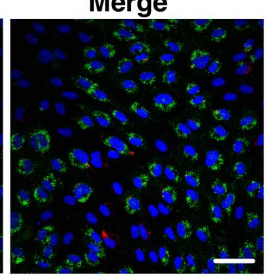

E.2

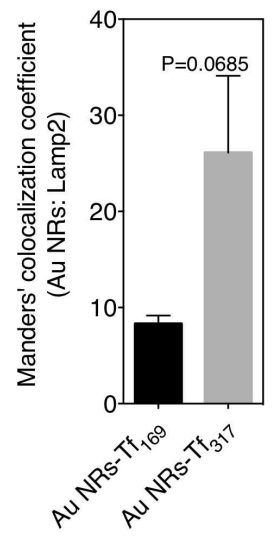

Fig 4. Internalization of the formulations in a in vitro human BBB model. (A) Schematic representation of the protocol used. The in vitro $\mathrm{BBB}$ model was exposed to the formulations (Au NPs: $100 \mu \mathrm{g} / \mathrm{mL}$; Au NRs: $50 \mu \mathrm{g} / \mathrm{mL}$ ) for $2 \mathrm{~h}$, after which the formulations were removed, cells were washed and trypsinized. Cells were characterized by ICP-MS, flow cytometry and immunofluorescence. (B) Surface expression of the Tf receptor in brain ECs at basal conditions or after incubation for $2 \mathrm{~h}$ with the formulations, was evaluated by flow cytometry. The percentages shown in the scatter plots were calculated based on the isotype controls (dark blue). Results are Mean \pm SEM ( $n=2$ independent experiments, 3 technical replicates per independent experiment). (C) Amount of Au NPs and (D) Au NRs within the ECs at time $2 \mathrm{~h}$ (the results were normalized to the initial concentration of NPs/NRs). Results are Mean \pm SEM ( $n=2$ independent experiments, 3 technical replicates per independent experiment). $* * P<0.01$ and $* * * P<0.001$. Statistical analyses were performed by One-way ANOVA followed by a Dunnett post-test (comparison of all conditions). $* * P<0.01$, $* * * P<0.001$. (E.1) Confocal microscopy images of ECs exposed to Au NRs 
labeled with a fluorescent probe for $8 \mathrm{~h}$. Images show the colocalization of $\mathrm{Au}$ NRs with the Lamp2-lysosomal compartment. Bar corresponds to $50 \mu \mathrm{m}$. (E.2) Quantification of the colocalization expressed by Manders' coefficient determined by ImageJ. Results are Mean \pm SEM ( $\mathrm{n}=2$ independent experiments, 3 technical replicates per independent experiment). (What was the statistical test?)

The different uptake behavior of the nanoformulations could be ascribed to differences in TfR expression level of ECs and/or the extent of TfR recycling after binding to the formulation [33]. Therefore, we evaluate the expression of TfR by flow cytometry (Fig. 4A, B). No significant differences were observed in the expression of the TfR of ECs before and after exposure to Au NRs-Tf 169 and $\mathrm{Au} \mathrm{NRs}_{16 \mathrm{~T}}$ (Fig. 4B). We evaluated then the intracellular trafficking of the NP formulations by confocal microscopy. The formulation $\mathrm{Au}$ NRs-Tf $\mathrm{T}_{317}$ had higher co-localization with lysosome-associated membrane protein 2 (Lamp2) than Au NRs-Tf ${ }_{169}$, thus indicating that NRs with high density of Tf accumulated at higher levels in lysosomes than NRs with moderate density of $\mathrm{Tf}$ (Fig. 4E). To further understand the impact of $\mathrm{Tf}$ peptide density in the internalization/intracellular transport, we estimated the dissociation constant $(\mathrm{Kd})$ of the $\mathrm{Au}$ NRs-

$\mathrm{Tf}_{17 / 169 / 317}$ and thus the avidity of Au NRs formulation with $\mathrm{TfR}$. On contrary to Au NRs-Tf 17 and $\mathrm{Au}$ NRs-Tf $f_{317}, \mathrm{Au} \mathrm{NR}-\mathrm{Tf}_{169}$ had the highest $\mathrm{Kd}$, indicating the weaker binding with TfRs that led to higher internalization by ECs (Supplementary Fig. 9). Overall, our results show that the density of the Tf peptide on the surface of the NPs/NRs play an important role in the internalization and intracellular trafficking process. The formulation with medium density of Tf peptide has superior internalization, high $\mathrm{Kd}$ and less degradation in the lysosome.

\subsection{Transport of the nanoformulations across an in vitro human BBB model}

Next, we evaluated the transcytosis of Au NPs-Tf and Au NRs-Tf in the in vitro BBB model (Fig. 5A). The concentrations of the formulations (Au NPs: $100 \mu \mathrm{g} / \mathrm{mL}$; Au NRs: $50 \mu \mathrm{g} / \mathrm{mL}$ ) were chosen taking into account literature data [11], sensitivity of ICP-MS analyses (our preliminary 
results indicated that $\mathrm{Au}$ NPs below or equal $50 \mu \mathrm{g} / \mathrm{mL}$ had low cellular uptake and thus their detection was in the sensitivity limit of the ICP-MS, Supplementary Fig. 10) and formulation effect in BBB integrity (Au NRs above $50 \mu \mathrm{g} / \mathrm{mL}$ were slightly cytotoxic).
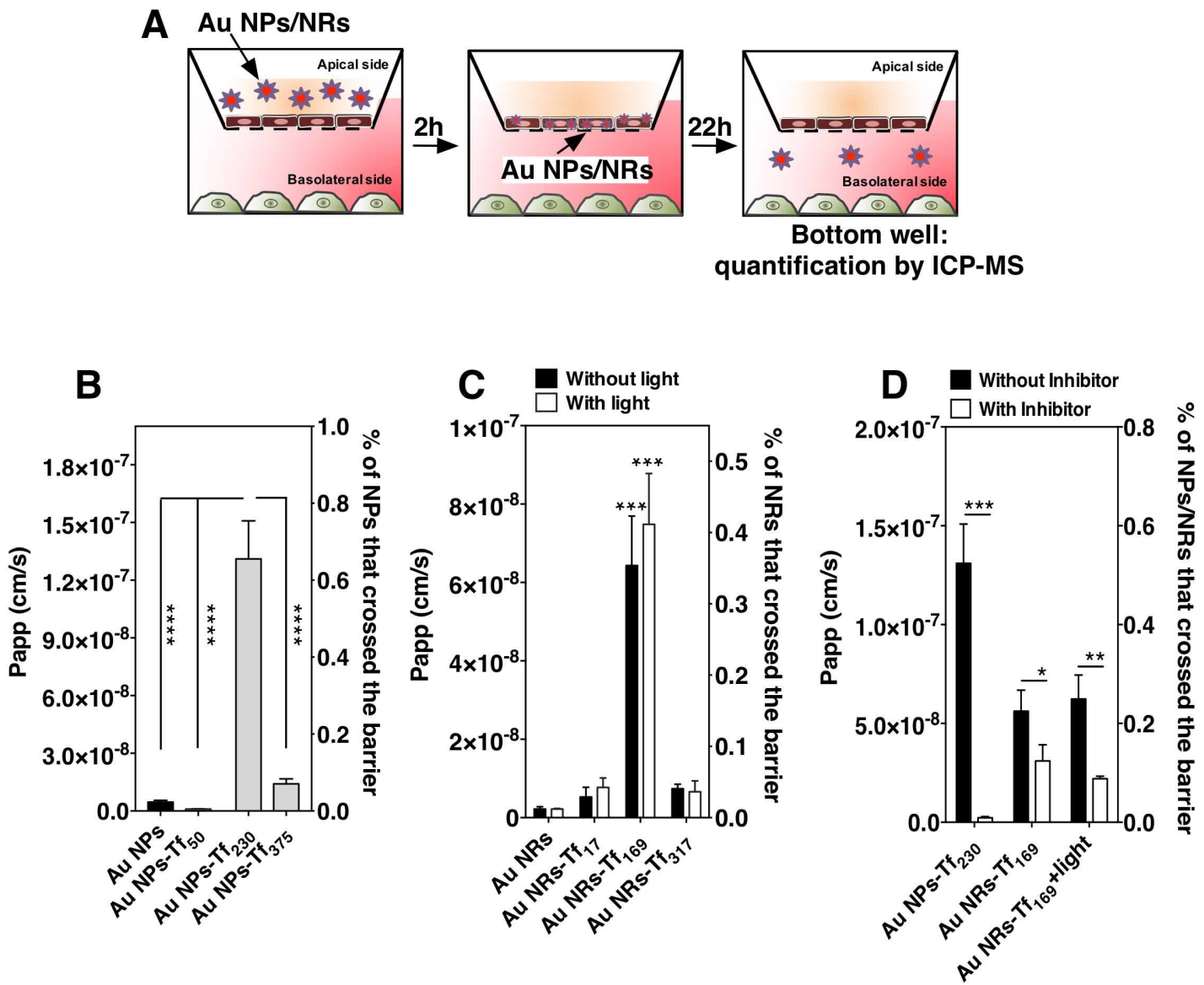

Fig 5. Permeability of the in vitro human BBB model to the formulations. (A) Schematic representation of the protocol used. The in vitro $\mathrm{BBB}$ model was exposed to the NP formulations (Au NPs: $100 \mu \mathrm{g} / \mathrm{mL}$; Au NRs: $50 \mu \mathrm{g} / \mathrm{mL}$ ) for $2 \mathrm{~h}$, after which the medium-containing the NPs was removed, cells were washed and new media was added. The BBB model was either exposed or not to a NIR laser $\left(2 \mathrm{Wcm}^{-2}, 2 \mathrm{~min}, 780 \mathrm{~nm}\right)$, and then incubated for additional $22 \mathrm{~h}$. Bottom media and pericytes were collected and evaluated by ICP-MS to determine Au content. Apparent permeability and $\%$ of initial concentration of (B) Au NPs and (C) Au NRs formulations. Results are Mean \pm SEM ( $n=2-3$ independent experiments, 3 technical replicates per independent experiment). $* * * P<0.001$ and $* * * * P<0.0001$. In $\mathrm{B}$ and $\mathrm{C}$, statistical analyses were performed by One-way ANOVA followed by a Dunnett post-test (comparison of all conditions). ${ }^{* *} P<0.01, * * * P<0.001$. (D) Apparent permeability and \% of initial concentration of Au NPs/Au NRs in the presence of the TfR inhibitor. Results are Mean \pm SEM ( $n=2-3$ independent experiments, 3 technical replicates per independent experiment). $* P<0.05, * * P<0.01$ and $* * * P<0.001$. Statistical analyses were performed by an unpaired t-test. 
The nanoformulations able to cross the BBB were quantified by ICP-MS (Fig. 5A). The formulations with medium density of $\mathrm{Tf}\left(\mathrm{Au}\right.$ NPs-Tf $\mathrm{T}_{230}$ or $\mathrm{Au} \mathrm{NRs}-\mathrm{Tf}_{169}$ ) showed the highest Papp (Au NPs-Tf $f_{230}: 1.3 \pm 0.1 \times 10^{-7} \mathrm{~cm} / \mathrm{s} ;$ Au NRs-Tf $\left.169: 6.4 \pm 0.1 \times 10^{-8} \mathrm{~cm} / \mathrm{s}\right)($ Fig. $5 \mathrm{~B}, \mathrm{C})$ likely due to the weak binding to TfR and the highest internalization by ECs (Supplementary Fig. 9 and Fig. 4B, C). The NIR laser exposure had no significant effect in the transcytosis of Au NRs (Fig. 5C). In conditions in which the integrity of BBB was impaired by the addition of mannitol, the Papp for Au NRs- $\mathrm{Tf}_{169}$ was $\approx 1.3 \times 10^{-4} \mathrm{~cm} / \mathrm{s}$, i.e., three orders of magnitude higher than without mannitol treated BBB $\left(\approx 1.5 \times 10^{-7} \mathrm{~cm} / \mathrm{s}\right)$, indicating that the integrity of $\mathrm{BBB}$ is important in controlling the transcytosis of NP formulations (Supplementary Fig. 6B). Importantly, the inhibition of clathrin endocytosis pathway, which mediates the internalization of the complex Tf:TfR [30], reduced significantly the transport of the formulations (Fig. 5D). The inhibitory effect was stronger for Au NPs- $\mathrm{Tf}_{230}$ than for $\mathrm{Au}$ NRs- $\mathrm{Tf}_{169}$ which may indicate the involvement of alternative transport mechanisms in the case of Au NRs. Further studies are needed to clarify this issue. NIR light exposure, in presence of inhibitor, did not improve the transport of NRs though the $\mathrm{BBB}$, as the internalized $\mathrm{Au}$ NRs in ECs had no significant heating effect as shown before (Fig. 2D). Overall, our results show that the nanoformulations with medium density of Tf showed the highest transport efficiency across the BBB. The transport of the NPs/NRs seems to be largely mediated by the TfR since the inhibition of its internalization has impact on the transport of the nanoformulations. Based on these results, formulations $\mathrm{Au}$ NPs- $\mathrm{Tf}_{230}$ and $\mathrm{Au} \mathrm{NRs}-\mathrm{Tf}_{169}$ were selected for subsequent in vivo studies.

\subsection{Accumulation of the nanoformulations in the neurogenic regions of the brain}

Next, we evaluated the capacity of formulations to cross the BBB and accumulate in the neurogenic regions of mouse brain. The formulations $(200 \mu \mathrm{L}$ of $5 \mathrm{mg} / \mathrm{mL})$ were intravenously 
injected into the tail vein and allowed to circulate for $2 \mathrm{~h}$ before the animals being sacrificed (Fig. 6A). This time was chosen based on previous studies [11, 14, 45]. Animals injected with Au NRs$\mathrm{Tf}_{169}$ (but not the ones injected with $\mathrm{Au}$ NPs- $\mathrm{Tf}_{230}$ because this formulation is not activated by NIR), were shaved in the head and exposed to NIR light for $2 \mathrm{~min}, 1 \mathrm{~h}$ post administration of Tf conjugated NRs (Fig. 6A). To reduce the effect of cerebral intravascular accumulation of the formulations, cerebral perfusion was performed before brain collection.

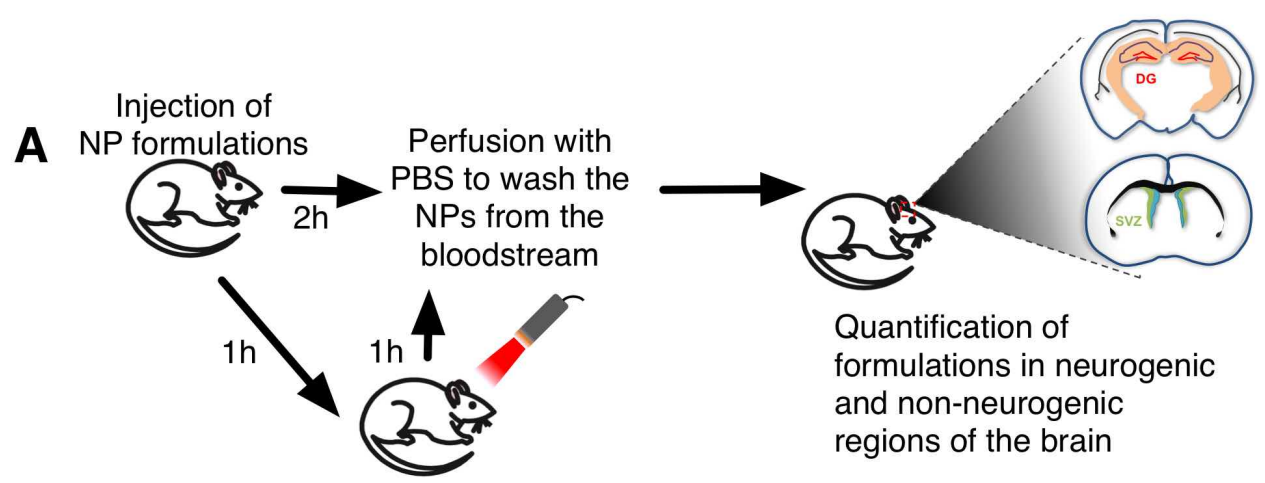

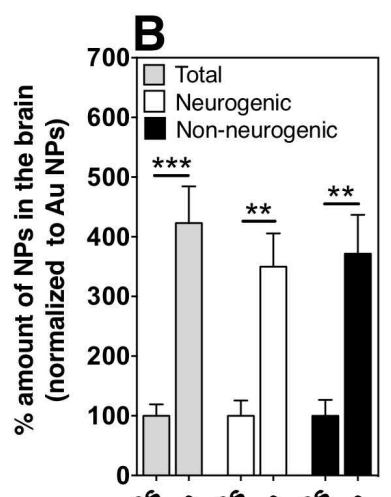

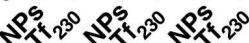

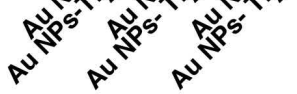

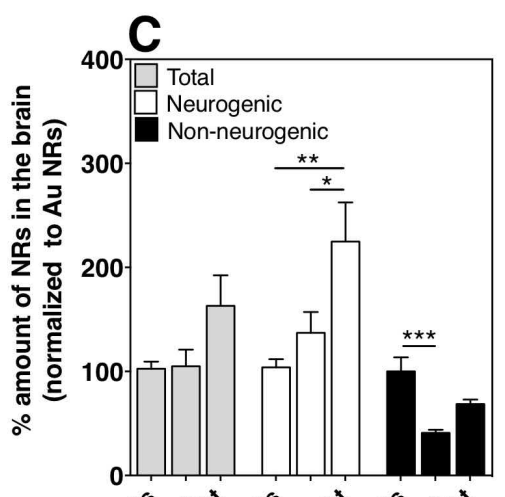

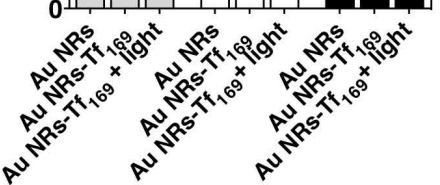

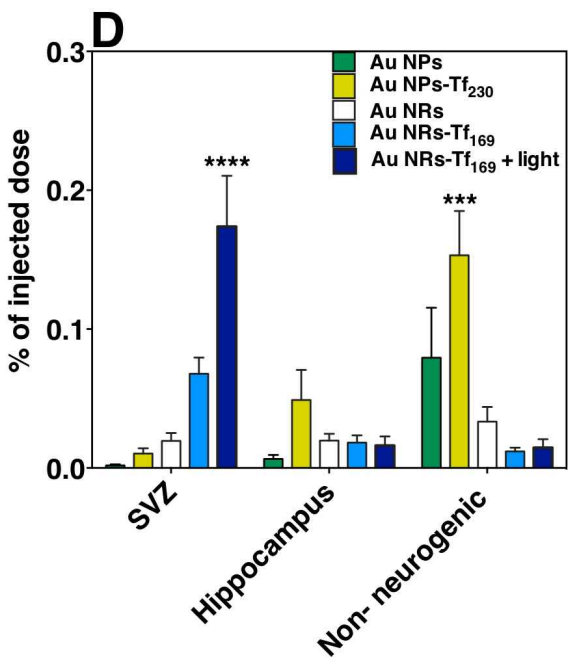

Fig 6. Accumulation of the nanoformulations in the brain. (A) Scheme illustrating the methodology used. In case of Au NRs, the animals were exposed to a NIR laser $\left(2 \mathrm{Wcm}^{-2}\right.$, for $\left.2 \mathrm{~min}\right)$ at time $1 \mathrm{~h}$. Two hours post-injection, the animals were sacrificed and the different brain regions were collected for ICP-MS analysis. (B and C) Quantification of formulations (Au NPs or Au NRs) in total brain, neurogenic (SVZ and hippocampus) and non-neurogenic (cortex) regions, using ICP-MS analyses. (D) Quantification of Au content for each condition in the different regions normalized to the initial $\mathrm{Au}$ administrated (1 mg per animal). Results are average \pm SEM ( $\mathrm{n}=6-9$ animals). $* P<0.05$, $* * P<0.01, * * * P<0.001$ and $* * * * P<0.0001$. Statistical analyses were performed by an unpaired $\mathrm{t}-$ test (B) and One-way ANOVA followed by a Dunnett post-test (C and D). 
Our results show that Au NPs- $\mathrm{Tf}_{230}$ accumulated at higher concentration in the brain (both in neurogenic and non-neurogenic regions) than bare Au NPs (Fig. 6B). In line with the results obtained for the in vitro human BBB model, Au NPs- $\mathrm{Tf}_{230}$ accumulated in the brain in higher concentrations than Au NPs-Tf ${ }_{375}$ (Supplementary Fig. 11). Moreover, Au NRs-Tf 169 accumulated in the brain at higher concentrations than bare Au NRs (Fig. 6C). Interestingly, Au NRs-Tf 169 exposed to a NIR laser accumulated at higher concentrations in the brain, particularly in the neurogenic regions, than the same formulation without laser activation (Fig. 6C, 6D). Although animals treated with $\mathrm{Au}$ NRs- $\mathrm{Tf}_{169}$ and exposed to a NIR laser or animals treated with $\mathrm{Au}$ NPs-Tf 230 (but not exposed to NIR laser) showed similar concentration of $\mathrm{Au}$ in the brain; $\mathrm{Au}$ NRs-Tf $\mathrm{f}_{169}$ accumulated preferentially at the SVZ while Au NPs- $\mathrm{Tf}_{230}$ accumulated at the non-neurogenic regions (Fig. 6D). Importantly, the accumulation of $\mathrm{Au}$ NRs- $\mathrm{Tf}_{169}$ at the $\mathrm{SVZ}$ region does not seem to induce neural degeneration (relatively to $\mathrm{SVZ}$ regions not exposed to nanoformulations) as demonstrated by Fluoro Jade C staining (Supplementary Fig. 12).

It is known that the permeability of the BBB increases with brain hyperthermia [47]. To determine whether the high accumulation of $\mathrm{Au}$ NRs- $\mathrm{Tf}_{169}$ after laser exposure is indeed mediated by a transient opening of the BBB, we have measured the accumulation of Evans blue in the brain after 1 or $24 \mathrm{~h}$ of laser irradiation (Fig. 7). Evans blue is a non-toxic dye that binds to serum albumin and thus in normal physiological conditions does not cross the BBB. Our results show a temporal disruption of the $\mathrm{BBB}$ at time $2 \mathrm{~h}$ post injection (corresponding to $1 \mathrm{~h}$ after laser irradiation), as confirmed by the extravasation of Evans blue on the brain (Fig. 7A, B.1) and in particular at the SVZ region (Fig. 7B.2). The disruption of the BBB was not maintained 24 h posirradiation, indicating the recovery of BBB permeability to a normal level (Fig. 7A, B). 

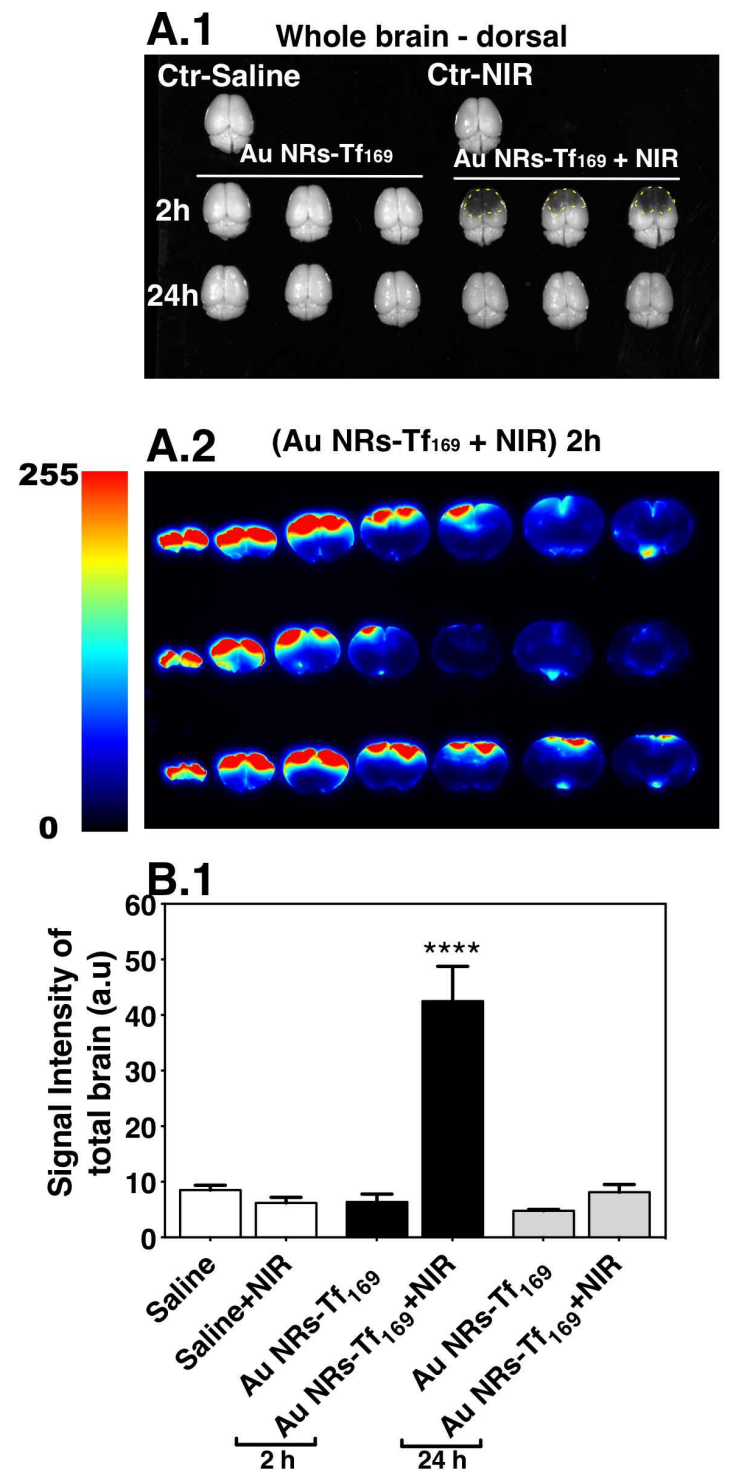

Whole brain - ventral

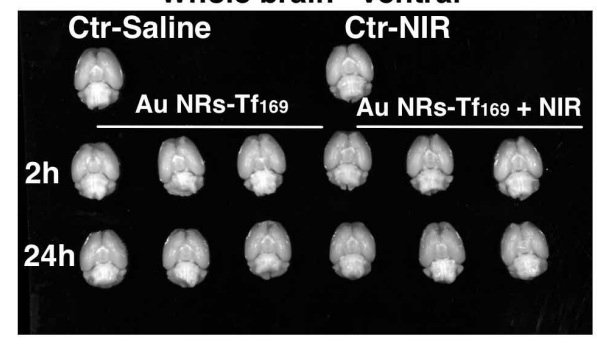

(Au NRs-Tf $169+\mathrm{NIR}) 24 \mathrm{~h}$
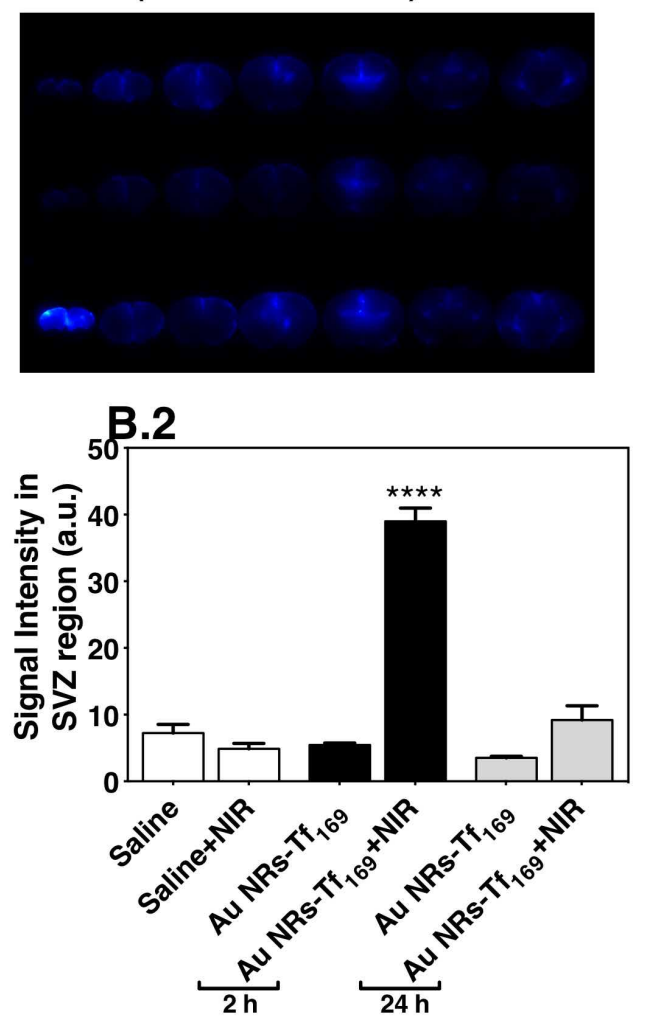

Fig 7. In vivo transient BBB opening. Animals were injected intravenously with $\mathrm{Au}$ NR-Tf ${ }_{169}$. After $1 \mathrm{~h}$, the head of the animals were exposed to a NIR laser at $780 \mathrm{~nm}$ for $2 \mathrm{~min}$. The animals were then sacrificed at times 2 and $24 \mathrm{~h}$ post-injection. (A.1) Mice brain images (ventral and dorsal) obtained by a ChemiDoc MP camera. Dark regions in the front areas (dashed yellow) of the brain were observed at time $2 \mathrm{~h}$ after NRs formulation injection (i.e. $1 \mathrm{~h}$ after laser activation). No dark regions were observed at time $24 \mathrm{~h}$ indicating BBB recovery. (A.2) Brain slice images show the extravasation of Evans blue in z. The images were obtained by a ChemiDoc camera using the intrinsic fluorescence of Evans blue in the region of 665-715 nm. Red means high extravasation of Evans blue. Quantification of signal intensities using the Mean Grey Value (Mean/area of the region) of (B.1) total brain and (B.2) SVZ region. Results are Mean \pm SEM ( $n=3$ animals per time point and experimental group). $* * * * P<0.0001, \mathrm{Au} \mathrm{NRs}^{-\mathrm{Tf}_{169}}+\mathrm{NIR} 2 \mathrm{~h}$ versus all other conditions. Statistical analyses were performed by One-way ANOVA followed by a Dunnett post-test. 


\section{DISCUSSION}

In this study, we have screened nanoformulations for their ability to cross the BBB and accumulate preferentially in the neurogenic regions of the brain. The nanoformulations varied according to their morphology (spherical or rod-shape), number of Tf peptides per NP/NR surface and responsiveness to light. Our results show that although a medium density of $\mathrm{Tf}$ on the surface of the formulation is important for the internalization and for the effective transport of the NP formulation through the $\mathrm{BBB}$, the activation of the formulation by a NIR laser leads to its preferential accumulation in the neurogenic regions.

Our study uses new tools to investigate the permeability of the formulations into the brain. In the current work we have used an in vitro human $\mathrm{BBB}$ model developed by us [25] to screen the transport of the formulations. Therefore, the results obtained might have significance in the context of human brain delivery. In addition, we have used formulations that take advantage of new bioconjugation chemistry principles and efficient presentation of the targeting peptide. The formulations present the Tf peptide by a flexible polyethylene glycol arm to facilitate the interaction with TfR. To stabilize the NP formulation and prevent protein adsorption, additional polyethylene glycol molecules with low molecular weight were reacted with the surface of the NP to saturate the remaining Au NP surface.

Studies have reported the targeting of NP formulations to the TfR as an efficient strategy to cross the BBB $[11,32,33,48]$, being the avidity to the receptor very important for the effectiveness of the transport through the BBB $[32,33]$. In this work, we have used a Tf peptide rather than a Tf protein or an antibody to target the TfR. We selected Tf peptide because it is a small molecule, it does not compete with the natural Tf protein for its receptor [49], and it is likely more stable than the Tf protein. We have studied for the first time the combined effect of morphology with Tf density. Our in vitro data indicate that Au NPs have lower permeability than Au NRs when both formulations were used at similar concentration $(50 \mu \mathrm{g} / \mathrm{mL})$ in the BBB model (Supplementary Fig. 
10). This agrees with previous a previous study showing that nanorods exhibited higher adhesion to brain ECs, as well as brain accumulation, than spherical NPs [50]. This is likely due to the fact that elongated NPs have a more thorough contact with cell membrane and Tf receptor than spherical NPs. It is also possible that the higher weight of Au NRs than Au NPs per particle may increase their permeation by gravity [51]. Moreover, we show in vitro that $\mathrm{Au}$ NPs-Tf ${ }_{230}$ have a Papp value of $1.3 \times 10^{-7} \mathrm{~cm} / \mathrm{s}$, which is in the same order of magnitude found for other formulations described in the literature $\left(1.4 \times 10^{-7}\right.$ and $0.2 \times 10^{-7} \mathrm{~cm} / \mathrm{s}$ for Au NPs-Tf and Au NPs-miniAP4, respectively) [11, 34]. Our results agree with previous studies showing that a high density of $\mathrm{Tf}$ per formulation decreases its transport efficiency through the BBB $[13,18]$.

Binding behavior of ligands to receptors plays an important role in their receptor-mediated endocytosis. Binding behavior depends on conformation and availability of ligands to receptor. Au NRs- $\mathrm{Tf}_{169}$ have higher $\mathrm{Kd}$ than other formulations, indicating a weaker avidity with $\mathrm{TfR}$ and thus a

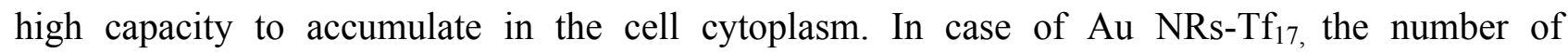
conjugated Tf peptide per NR might be too low in order to interact optimally with TfR. On the other hand, $\mathrm{Au}$ NRs- $\mathrm{Tf}_{317}$ have stronger avidity (low $\mathrm{Kd}$ ) with $\mathrm{TfR}$, which ultimately reduce the internalization of NRs. It is likely that in case of $\mathrm{Au}$ NPs- $\mathrm{Tf}_{370} / \mathrm{Au} \mathrm{NRs}-\mathrm{Tf}_{317}$, $\mathrm{Tf}$ peptides adopt favorable conformations that interact strongly with TfR. Previous study have also shown that increasing size and antibody content on NPs enhances the NP avidity to cell surface receptors [52]. Our results, are further in line with other data recently reported [33], indicating that nanoformulations with higher density of $\mathrm{Tf}$ peptide (higher avidity) present higher colocalization with Lamp2, which means that those nanoformulations were entrapped in the cellular lysosomes. Interestingly, in contrast to previous studies [33], the formulations with higher density of Tf showed the lowest cellular internalization, which might be related to the low availability of TfR over time.

Not only does the density of Tf peptide but also the laser activation of Au NRs modulates the transport of NRs across the $\mathrm{BBB}$ due to generation of local heat that induce the opening of the 
barrier. In vitro results showed that $\mathrm{BBB}$ exposure to $\mathrm{Au}$ NRs followed by their activation with a NIR laser after a washing step, it was not detrimental for BBB integrity and permeability. However, when the cells were irradiated in the presence of $\mathrm{Au} \mathrm{NRs- \textrm {Tf } _ { 1 6 9 }}$ (situation that is closer to in vivo studies) we observed an increase in the permeability, probably due to the local heating. Indeed, temperature profile measurements performed in the in vitro $\mathrm{BBB}$ model after exposure and irradiation of $\mathrm{Au}$ NRs indicate that there was a significant increment in temperature. This phenomenon is known to increase temporarily the permeability of the BBB [21,47]. It is important to note that according to our in vitro results the duration of the heating has an important role in the opening of the BBB.

Our results show that the in vivo activation of Au NRs by NIR laser lead to the preferential accumulation of the formulations into the neurogenic niches. Previous studies have demonstrated the accumulation of NPs in neurogenic niches particularly in the hippocampus after a systemic administration $[53,54]$; however, the requirement for a preferential accumulation remained elusive. Our results show that $\mathrm{Au}$ NRs- $\mathrm{Tf}_{169}$ after laser activation accumulate preferentially in the neurogenic regions, particularly SVZ region, relatively to $\mathrm{Au} \mathrm{NPs}-\mathrm{Tf}_{230} . \mathrm{SVZ}$ niche is the largest germinal area of the adult human brain, acting as a reservoir of adult NSCs that can be activated for brain repair [55]. It has been shown that the BBB at the SVZ is more permissive and leaky than the BBB in other regions of the brain $[55,56]$. This leakiness is characterized by a reduction in astrocytes endfeet and pericytes coverage as well as loss of ZO-1 and occludin in some areas of the blood vessels [56]. Interestingly, the BBB at SVZ region is more permissive than at hippocampus region [56-58]. We hypothesize that the transient heating of Au NRs- $\mathrm{Tf}_{169}$ upon laser exposure opens of the most permissive points in the $\mathrm{BBB}$ allowing the accumulation of NR formulation. This is confirmed by the Evans blue analyses. A transient increase in the BBB permeability is observed at time $1 \mathrm{~h}$ post laser activation but disappears at time $23 \mathrm{~h}$ post laser activation. The concept of "transient permeability of BBB" has been explored in previous studies by the use of formulations 
with BBB-disruptive ligands $[59,60]$ or photothermic properties $[21,61]$; however, our study is the first to demonstrate that a preferential accumulation of the formulation after light activation in the neurogenic niches.

In the present work, we have used Au NPs/Au NRs for proof of concept studies because it is easy to modify these formulations with Tf peptides and to monitor them either in vitro or in vivo. It is likely possible to degrade Au NRs after their accumulation in the brain by photofragmentation induced by pulsed NIR lasers [62]; however, this requires pulsed lasers with high energy which might raises safety concerns. To facilitate the biological degradation of the NRs without laser activation, future studies should explore the development of nanoformulations with an organic degradable core coated with a thin layer of gold. As alternative, iron oxide NPs that produce heat after activation by a low radiofrequency field [21] might be used. This approach has also limitations because it requires the proximity of the brain to the magnet $(30-50 \mathrm{~cm})$ [63] and the magnetic field strength allowed in humans ( $8 \mathrm{~T}$ for adults) might not be sufficient for the generation of enough heat. Finally, another approach to facilitate the degradation of the nanoformulations is by the use of biodegradable polydopamine NPs. These nanoformulations heat after NIR laser exposure [64] and thus facilitate the clinical translation of the principles ( $\mathrm{Tf}$ density, heating by light, nanocarrier morphology) identified in this work using Au NRs.

The total amount of Au NPs-Tf ${ }_{230}$ and Au NRs- $\mathrm{Tf}_{169}$ accumulated in the brain was in the order of $0.3 \%$ of the injected dose (therefore, $3 \mu \mathrm{g}$ of NPs per mouse brain). It is unclear whether this quantity is enough to deliver biomolecules to modulate the neurogenic niches of the brain. Further research is needed to address this issue. However, the total amount that reached the brain is in the same order as the ones reported by other authors $[13,65]$.

\section{CONCLUSION}


In conclusion, we have identified a nanoformulation that is internalized by brain ECs, mostly by receptor-mediated endocytosis, and is able to induce BBB opening after irradiation by a NIR laser. The combination of these features contributes for the preferential accumulation of the formulation in the SVZ of mouse brain, after intravenous administration. The formulation, having a medium density of $\mathrm{Tf}$, has superior transport along the BBB as compared to others, as confirmed by in vitro and in vivo tests. The transport through the $\mathrm{BBB}$ is due to the low avidity of the formulation to the TfR as well as low accumulation in the endolysomal compartment. The activation of the formulation with a NIR laser leads to its preferential accumulation in the neurogenic niche. The specific accumulation of the formulation in the brain, particularly at the neurogenic regions, opens new possibilities for brain repair in the context of neurodegenerative and ischemic diseases.

\section{Supporting Information}

Supporting information is available from Science Direct Library or from the author.

\section{Acknowledgements}

LF would like to thank ERC project Nanotrigger (Ref: 307384), Portugal2020 project StrokeTherapy (Project reference: 3386) and EC project ERA chair (ERA@UC, ref. 669088). CP and AC would like to thank the support of FCT -Science and Technology Foundation for the fellowships (SFRH/BD/51678/2011; SFRH/BPD/69643/2010 respectively).

\section{References}

[1] D. Mozaffarian, E.J. Benjamin, A.S. Go, D.K. Arnett, M.J. Blaha, M. Cushman, S. de Ferranti, J.P. Despres, H.J. Fullerton, V.J. Howard, M.D. Huffman, S.E. Judd, B.M. Kissela, D.T. Lackland, J.H. Lichtman, L.D. Lisabeth, S. Liu, R.H. Mackey, D.B. Matchar, D.K. McGuire, E.R. Mohler, 3rd, C.S. Moy, P. Muntner, M.E. Mussolino, K. Nasir, R.W. Neumar, G. Nichol, L. Palaniappan, D.K. Pandey, M.J. Reeves, C.J. Rodriguez, P.D. Sorlie, J. Stein, A. Towfighi, T.N. Turan, S.S. Virani, J.Z. Willey, D. Woo, R.W. Yeh, M.B. Turner, Heart disease and stroke statistics--2015 update: a report from the American Heart Association, Circulation, 131 (2015) e29-322. 
[2] S. Aday, R. Cecchelli, D. Hallier-Vanuxeem, M.P. Dehouck, L. Ferreira, Stem Cell-Based Human Blood-Brain Barrier Models for Drug Discovery and Delivery, Trends Biotechnol, 34 (2016) 382-393.

[3] O. Lindvall, Z. Kokaia, Stem cells in human neurodegenerative disorders--time for clinical translation?, The Journal of clinical investigation, 120 (2010) 29-40.

[4] J. Maia, T. Santos, S. Aday, F. Agasse, L. Cortes, J.O. Malva, L. Bernardino, L. Ferreira, Controlling the neuronal differentiation of stem cells by the intracellular delivery of retinoic acidloaded nanoparticles, ACS nano, 5 (2011) 97-106.

[5] T. Santos, R. Ferreira, J. Maia, F. Agasse, S. Xapelli, L. Cortes, J. Braganca, J.O. Malva, L. Ferreira, L. Bernardino, Polymeric nanoparticles to control the differentiation of neural stem cells in the subventricular zone of the brain, ACS nano, 6 (2012) 10463-10474.

[6] M. Esteves, A.C. Cristovao, T. Saraiva, S.M. Rocha, G. Baltazar, L. Ferreira, L. Bernardino, Retinoic acid-loaded polymeric nanoparticles induce neuroprotection in a mouse model for Parkinson's disease, Frontiers in aging neuroscience, 7 (2015) 20.

[7] C. Saraiva, J. Paiva, T. Santos, L. Ferreira, L. Bernardino, MicroRNA-124 loaded nanoparticles enhance brain repair in Parkinson's disease, Journal of controlled release : official journal of the Controlled Release Society, 235 (2016) 291-305.

[8] G. Ming, H. Song, Adult Neurogenesis in the Mammalian Brain: Significant Answers and Significant Questions, Neuron, 70 (2011) 687-702.

[9] T. Santos, J. Maia, F. Agasse, S. Xapelli, L. Ferreira, L. Bernardino, Nanomedicine boosts neurogenesis: new strategies for brain repair, Integrative biology : quantitative biosciences from nano to macro, 4 (2012) 973-981.

[10] T. Santos, C. Boto, C.M. Saraiva, L. Bernardino, L. Ferreira, Nanomedicine Approaches to Modulate Neural Stem Cells in Brain Repair, Trends Biotechnol, 34 (2016) 437-439.

[11] R. Prades, S. Guerrero, E. Araya, C. Molina, E. Salas, E. Zurita, J. Selva, G. Egea, C. LopezIglesias, M. Teixido, M.J. Kogan, E. Giralt, Delivery of gold nanoparticles to the brain by conjugation with a peptide that recognizes the transferrin receptor, Biomaterials, 33 (2012) 71947205.

[12] Y. Cui, Q. Xu, P.K. Chow, D. Wang, C.H. Wang, Transferrin-conjugated magnetic silica PLGA nanoparticles loaded with doxorubicin and paclitaxel for brain glioma treatment, Biomaterials, 34 (2013) 8511-8520.

[13] D.T. Wiley, P. Webster, A. Gale, M.E. Davis, Transcytosis and brain uptake of transferrincontaining nanoparticles by tuning avidity to transferrin receptor, P Natl Acad Sci USA, 110 (2013) 8662-8667.

[14] M. Shilo, M. Motiei, P. Hana, R. Popovtzer, Transport of nanoparticles through the bloodbrain barrier for imaging and therapeutic applications, Nanoscale, 6 (2014) 2146-2152.

[15] R. Gromnicova, H.A. Davies, P. Sreekanthreddy, I.A. Romero, T. Lund, I.M. Roitt, J.B. Phillips, D.K. Male, Glucose-coated gold nanoparticles transfer across human brain endothelium and enter astrocytes in vitro, PloS one, 8 (2013) e81043.

[16] A.P. Mann, P. Scodeller, S. Hussain, J. Joo, E. Kwon, G.B. Braun, T. Molder, Z.G. She, V.R. Kotamraju, B. Ranscht, S. Krajewski, T. Teesalu, S. Bhatia, M.J. Sailor, E. Ruoslahti, A peptide for targeted, systemic delivery of imaging and therapeutic compounds into acute brain injuries, Nat Commun, 7 (2016).

[17] A. Joseph, C. Contini, D. Cecchin, S. Nyberg, L. Ruiz-Perez, J. Gaitzsch, G. Fullstone, X.H. Tian, J. Azizi, J. Preston, G. Volpe, G. Battaglia, Chemotactic synthetic vesicles: Design and applications in blood-brain barrier crossing, Sci Adv, 3 (2017).

[18] Y.J. Yu, Y. Zhang, M. Kenrick, K. Hoyte, W. Luk, Y.M. Lu, J. Atwal, J.M. Elliott, S. Prabhu, R.J. Watts, M.S. Dennis, Boosting Brain Uptake of a Therapeutic Antibody by Reducing Its Affinity for a Transcytosis Target, Sci Transl Med, 3 (2011). 
[19] M.E. Downs, A. Buch, C. Sierra, M.E. Karakatsani, T. Teichert, S.S. Chen, E.E. Konofagou, V.P. Ferrera, Long-Term Safety of Repeated Blood-Brain Barrier Opening via Focused Ultrasound with Microbubbles in Non-Human Primates Performing a Cognitive Task (vol 10, e0125911, 2015), PloS one, 10 (2015).

[20] D. McMahon, K. Hynynen, Acute Inflammatory Response Following Increased Blood-Brain Barrier Permeability Induced by Focused Ultrasound is Dependent on Microbubble Dose, Theranostics, 7 (2017) 3989-4000.

[21] S.N. Tabatabaei, H. Girouard, A.S. Carret, S. Martel, Remote control of the permeability of the blood-brain barrier by magnetic heating of nanoparticles: A proof of concept for brain drug delivery, Journal of controlled release : official journal of the Controlled Release Society, 206 (2015) 49-57.

[22] Z.Y. Liu, X.L. Gao, T. Kang, M.Y. Jiang, D.Y. Miao, G.Z. Gu, Q.Y. Hu, Q.X. Song, L. Yao, Y.F. Tu, H.Z. Chen, X.G. Jiang, J. Chen, B6 Peptide-Modified PEG-PLA Nanoparticles for Enhanced Brain Delivery of Neuroprotective Peptide, Bioconjugate Chem, 24 (2013) 997-1007.

[23] R. Patil, A.V. Ljubimov, P.R. Gangalum, H. Ding, J. Portilla-Arias, S. Wagner, S. Inoue, B. Konda, A. Rekechenetskiy, A. Chesnokova, J.L. Markman, V.A. Ljubimov, D.B. Li, R.S. Prasad, K.L. Black, E. Holler, J.Y. Ljubimova, MRI Virtual Biopsy and Treatment of Brain Metastatic Tumors with Targeted Nanobioconjugates: Nanoclinic in the Brain, ACS nano, 9 (2015) 55945608.

[24] J.K. Saucier-Sawyer, Y. Deng, Y.E. Seo, C.J. Cheng, J.W. Zhang, E. Quijano, W.M. Saltzman, Systemic delivery of blood-brain barrier-targeted polymeric nanoparticles enhances delivery to brain tissue, J Drug Target, 23 (2015) 736-749.

[25] R. Cecchelli, S. Aday, E. Sevin, C. Almeida, M. Culot, L. Dehouck, C. Coisne, B. Engelhardt, M.P. Dehouck, L. Ferreira, A Stable and Reproducible Human Blood-Brain Barrier Model Derived from Hematopoietic Stem Cells, PloS one, 9 (2014).

[26] B.J. Quirk, G. Brandal, S. Donlon, J.C. Vera, T.S. Mang, A.B. Foy, S.M. Lew, A.W. Girotti, S. Jogal, P.S. LaViolette, J.M. Connelly, H.T. Whelan, Photodynamic therapy (PDT) for malignant brain tumors Where do we stand?, Photodiagn Photodyn, 12 (2015) 530-544.

[27] J. Turkevich, P.C. Stevenson, J. Hillier, A study of the nucleation and growth processes in the synthesis of colloidal gold, Discussions of the Faraday Society, 11 (1951) 55-75.

[28] B. Nikoobakht, M.A. El-Sayed, Preparation and growth mechanism of gold nanorods (NRs) using seed-mediated growth method, Chem Mater, 15 (2003) 1957-1962.

[29] S. Bolte, F.P. Cordelieres, A guided tour into subcellular colocalization analysis in light microscopy, J Microsc, 224 (2006) 213-232.

[30] C.S. Paulo, M.M. Lino, A.A. Matos, L.S. Ferreira, Differential internalization of amphotericin B--conjugated nanoparticles in human cells and the expression of heat shock protein 70 , Biomaterials, 34 (2013) 5281-5293.

[31] L.C. Schmued, C.C. Stowers, A.C. Scallet, L. Xu, Fluoro-Jade C results in ultra high resolution and contrast labeling of degenerating neurons, Brain research, 1035 (2005) 24-31.

[32] D.T. Wiley, P. Webster, A. Gale, M.E. Davis, Transcytosis and brain uptake of transferrincontaining nanoparticles by tuning avidity to transferrin receptor, Proc Natl Acad Sci U S A, 110 (2013) 8662-8667.

[33] J. Niewoehner, B. Bohrmann, L. Collin, E. Urich, H. Sade, P. Maier, P. Rueger, J.O. Stracke, W. Lau, A.C. Tissot, H. Loetscher, A. Ghosh, P.O. Freskgard, Increased brain penetration and potency of a therapeutic antibody using a monovalent molecular shuttle, Neuron, 81 (2014) 49-60.

[34] B. Oller-Salvia, M. Sanchez-Navarro, S. Ciudad, M. Guiu, P. Arranz-Gibert, C. Garcia, R.R. Gomis, R. Cecchelli, J. Garcia, E. Giralt, M. Teixido, MiniAp-4: A Venom-Inspired Peptidomimetic for Brain Delivery, Angew Chem Int Ed Engl, 55 (2016) 572-575.

[35] H. Chen, L. Shao, Q. Li, J. Wang, Gold nanorods and their plasmonic properties, Chemical Society reviews, 42 (2013) 2679-2724. 
[36] A.M. Alkilany, L.B. Thompson, S.P. Boulos, P.N. Sisco, C.J. Murphy, Gold nanorods: their potential for photothermal therapeutics and drug delivery, tempered by the complexity of their biological interactions, Advanced drug delivery reviews, 64 (2012) 190-199.

[37] M. Akrami, S. Balalaie, S. Hosseinkhani, M. Alipour, F. Salehi, A. Bahador, I. Haririan, Tuning the anticancer activity of a novel pro-apoptotic peptide using gold nanoparticle platforms, Sci Rep, 6 (2016) 31030.

[38] K. Liu, Y. Zheng, X. Lu, T. Thai, N.A. Lee, U. Bach, J.J. Gooding, Biocompatible gold nanorods: one-step surface functionalization, highly colloidal stability, and low cytotoxicity, Langmuir, 31 (2015) 4973-4980.

[39] C. Yu, H. Nakshatri, J. Irudayaraj, Identity profiling of cell surface markers by multiplex gold nanorod probes, Nano Lett, 7 (2007) 2300-2306.

[40] K.K. Caswell, J.N. Wilson, U.H. Bunz, C.J. Murphy, Preferential end-to-end assembly of gold nanorods by biotin-streptavidin connectors, J Am Chem Soc, 125 (2003) 13914-13915.

[41] J.Y. Chang, H. Wu, H. Chen, Y.C. Ling, W. Tan, Oriented assembly of Au nanorods using biorecognition system, Chem Commun (Camb), (2005) 1092-1094.

[42] C.D. Walkey, J.B. Olsen, H. Guo, A. Emili, W.C. Chan, Nanoparticle size and surface chemistry determine serum protein adsorption and macrophage uptake, J Am Chem Soc, 134 (2012) 2139-2147.

[43] Q. Dai, C. Walkey, W.C. Chan, Polyethylene glycol backfilling mitigates the negative impact of the protein corona on nanoparticle cell targeting, Angew Chem Int Ed Engl, 53 (2014) 50935096.

[44] D.K. Bozanic, A.S. Luyt, L.V. Trandafilovic, V. Djokovic, Glycogen and gold nanoparticle bioconjugates: controlled plasmon resonance via glycogen-induced nanoparticle aggregation, Rsc Adv, 3 (2013) 8705-8713.

[45] S. Guerrero, E. Araya, J.L. Fiedler, J.I. Arias, C. Adura, F. Albericio, E. Giralt, J.L. Arias, M.S. Fernandez, M.J. Kogan, Improving the brain delivery of gold nanoparticles by conjugation with an amphipathic peptide, Nanomedicine (Lond), 5 (2010) 897-913.

[46] B. Poller, H. Gutmann, S. Krahenbuhl, B. Weksler, I. Romero, P.O. Couraud, G. Tuffin, J. Drewe, J. Huwyler, The human brain endothelial cell line hCMEC/D3 as a human blood-brain barrier model for drug transport studies, J Neurochem, 107 (2008) 1358-1368.

[47] E.A. Kiyatkin, H.S. Sharma, Permeability of the blood-brain barrier depends on brain temperature, Neuroscience, 161 (2009) 926-939.

[48] P. Ponka, C.N. Lok, The transferrin receptor: role in health and disease, Int J Biochem Cell B, 31 (1999) 1111-1137.

[49] J.H. Lee, J.A. Engler, J.F. Collawn, B.A. Moore, Receptor mediated uptake of peptides that bind the human transferrin receptor, Eur J Biochem, 268 (2001) 2004-2012.

[50] P. Kolhar, A.C. Anselmo, V. Gupta, K. Pant, B. Prabhakarpandian, E. Ruoslahti, S. Mitragotri, Using shape effects to target antibody-coated nanoparticles to lung and brain endothelium, P Natl Acad Sci USA, 110 (2013) 10753-10758.

[51] E.C. Cho, Q. Zhang, Y. Xia, The effect of sedimentation and diffusion on cellular uptake of gold nanoparticles, Nat Nanotechnol, 6 (2011) 385-391.

[52] W. Jiang, B.Y. Kim, J.T. Rutka, W.C. Chan, Nanoparticle-mediated cellular response is sizedependent, Nat Nanotechnol, 3 (2008) 145-150.

[53] Y.M. Tsai, C.F. Chien, L.C. Lin, T.H. Tsai, Curcumin and its nano-formulation: the kinetics of tissue distribution and blood-brain barrier penetration, International journal of pharmaceutics, 416 (2011) 331-338.

[54] S.K. Tiwari, S. Agarwal, B. Seth, A. Yadav, S. Nair, P. Bhatnagar, M. Karmakar, M. Kumari, L.K. Chauhan, D.K. Patel, V. Srivastava, D. Singh, S.K. Gupta, A. Tripathi, R.K. Chaturvedi, K.C. Gupta, Curcumin-loaded nanoparticles potently induce adult neurogenesis and reverse cognitive 
deficits in Alzheimer's disease model via canonical Wnt/beta-catenin pathway, ACS nano, 8 (2014) 76-103.

[55] A. Alvarez-Buylla, J.M. Garcia-Verdugo, Neurogenesis in adult subventricular zone, The Journal of neuroscience : the official journal of the Society for Neuroscience, 22 (2002) 629-634.

[56] M. Tavazoie, L. Van der Veken, V. Silva-Vargas, M. Louissaint, L. Colonna, B. Zaidi, J.M. Garcia-Verdugo, F. Doetsch, A specialized vascular niche for adult neural stem cells, Cell stem cell, 3 (2008) 279-288.

[57] T.D. Palmer, A.R. Willhoite, F.H. Gage, Vascular niche for adult hippocampal neurogenesis, The Journal of comparative neurology, 425 (2000) 479-494.

[58] J.S. Goldberg, K.K. Hirschi, Diverse roles of the vasculature within the neural stem cell niche, Regenerative medicine, 4 (2009) 879-897.

[59] C. Staat, C. Coisne, S. Dabrowski, S.M. Stamatovic, A.V. Andjelkovic, H. Wolburg, B. Engelhardt, I.E. Blasig, Mode of action of claudin peptidomimetics in the transient opening of cellular tight junction barriers, Biomaterials, 54 (2015) 9-20.

[60] X. Gao, J. Qian, S. Zheng, Y. Changyi, J. Zhang, S. Ju, J. Zhu, C. Li, Overcoming the bloodbrain barrier for delivering drugs into the brain by using adenosine receptor nanoagonist, ACS nano, 8 (2014) 3678-3689.

[61] H. Yuan, C.M. Wilson, J. Xia, S.L. Doyle, S. Li, A.M. Fales, Y. Liu, E. Ozaki, K. Mulfaul, G. Hanna, G.M. Palmer, L.V. Wang, G.A. Grant, T. Vo-Dinh, Plasmonics-enhanced and optically modulated delivery of gold nanostars into brain tumor, Nanoscale, 6 (2014) 4078-4082.

[62] Y.A. Attia, M.T. Flores-Arias, D. Nieto, C. Vazquez-Vazquez, G.F. De La Fuente, M.A. Lopez-Quintela, Transformation of Gold Nanorods in Liquid Media Induced by nIR, Visible, and UV Laser Irradiation, J Phys Chem C, 119 (2015) 13343-13349.

[63] B. Shapiro, K. Dormer, I.B. Rutel, A Two-Magnet System to Push Therapeutic Nanoparticles, AIP Conf Proc, 1311 (2010) 77-88.

[64] Y.L. Liu, K.L. Ai, J.H. Liu, M. Deng, Y.Y. He, L.H. Lu, Dopamine-Melanin Colloidal Nanospheres: An Efficient Near-Infrared Photothermal Therapeutic Agent for In Vivo Cancer Therapy, Adv Mater, 25 (2013) 1353-1359.

[65] A.J. Clark, M.E. Davis, Increased brain uptake of targeted nanoparticles by adding an acidcleavable linkage between transferrin and the nanoparticle core, P Natl Acad Sci USA, 112 (2015) 12486-12491. 